\title{
Explaining Inflation in the Aftermath of the Great Recession
}

\author{
Robert G. Murphy* \\ Department of Economics \\ Boston College \\ Chestnut Hill, MA 02467 \\ murphyro@bc.edu \\ January 2013 \\ Revised January 2014 \\ Published in the Journal of Macroeconomics, Volume 40, June 2014 \\ http://dx.doi.org/10.1016/j.jmacro.2014.01.002
}

\begin{abstract}
This paper considers whether the Phillips curve can explain the recent behavior of inflation in the United States. Standard formulations of the model predict that the ongoing large shortfall in economic activity relative to full employment should have led to deflation over the past several years. I confirm previous findings that the slope of the Phillips curve has varied over time and probably is lower today than it was several decades ago. This implies that estimates using historical data will overstate the responsiveness of inflation to present-day economic conditions. I modify the traditional Phillips curve to explicitly account for time variation in its slope and show how this modified model can explain the recent behavior of inflation without relying on anchored expectations. Specifically, I explore reasons why the slope might vary over time, focusing on implications of the sticky-price and sticky-information approaches to price adjustment. These implications suggest that the inflation environment and uncertainty about regional economic conditions should influence the slope of the Phillips curve. I introduce proxies to account for these effects and find that a Phillips curve modified to allow its slope to vary with uncertainty about regional economic conditions can best explain the recent path of inflation.
\end{abstract}

JEL Classification: E30, E31

Keywords: Inflation, Phillips curve, Great Recession, Sticky Information, Sticky Prices

\footnotetext{
* An earlier version of this paper was presented at the American Economic Association Meetings in San Diego, CA January 4-6, 2013. I would like to thank Mark Kurt and the referees for insightful comments on earlier drafts of this paper.
} 


\section{Introduction}

The economic downturn in the United States that began in late 2007, commonly known as the "Great Recession," was characterized by a sharp, although not historically unprecedented, decline in economic activity and a rapid rise in unemployment. Indeed, the recession of early 1980s exhibited a greater degree of economic slack. What has been unique about the recent recession is how long the weakness in the economy has persisted amidst a steep contraction in credit and a slow process of deleveraging debt. These characteristics set the recent recession apart from other post-World War II recessions and have led some to name it the "Second Great Contraction," the first one being the Great Depression. $^{1}$

Real GDP fell short of its potential level by nearly 7.5 percent at the depth of the recent downturn compared to just over 8.0 percent during the recession of the early 1980s. But recovery from that earlier recession was rapid, with the GDP gap closing to under 2 percent only one and a half years after the business-cycle trough and under 1 percent in less than three years. By contrast, the shortfall in GDP was 5.5 percent four years after the trough of the Great Recession. This prolonged period of slow growth and substantial weakness in the economy has raised concern among policymakers and analysts that downward pressure on prices could develop and lead to deflation. The successive rounds of quantitative easing by the Federal Reserve, along with its commitment to hold the federal funds rate near zero for the next few years, can be viewed in part as a response to this concern.

\footnotetext{
${ }^{1}$ Reinhart and Rogoff (2009) point out that the recent recession has seen a sharp contraction in credit and substantial deleveraging of debt, elements not typical of other post-World War II recessions. They suggest referring to the recent recession as the "Second Great Contraction" rather than the "Great Recession" because it has differed in kind and not just severity from previous recessions.
} 
Standard models of inflation in the short run build upon the work of Friedman (1968) and posit that inflation depends on expected inflation and slack in the economy, where slack is usually measured by either the gap between unemployment and its natural rate or the gap between GDP and its potential level. These models typically employ past inflation as a proxy for expected inflation, so that the change in inflation is determined by the gap variable. This canonical accelerationist Phillips curve has been modified and adapted by numerous authors over the last several decades. ${ }^{2}$

In a recent paper, Ball and Mazumder (2011) explore the ability of the Phillips curve model to explain the behavior of inflation during the Great Recession. They illustrate how a standard Phillips curve estimated using data since 1960 predicts deflation over the period 2008 to 2010, although actual inflation remained positive. After accounting for a recent decline in the slope of the Phillips curve by estimating the model on data only since 1985, and using median inflation to measure underlying core inflation, Ball and Mazumder find the model predicts median inflation close to its actual path through the end of 2010. But with substantial economic slack persisting beyond 2010, Ball and Mazumder find that the Phillips curve again predicts deflation, unless expectations about inflation are at least partially anchored to the Federal Reserve's target inflation rate.

This paper revisits the question of why the standard Phillips curve has predicted deflation over the past several years. In particular, I modify the Phillips curve to allow its slope to vary continuously through time. I consider implications of price-setting models when prices are costly to adjust and when information is costly to obtain as reasons for

\footnotetext{
${ }^{2}$ See, for example, Fuhrer (1995), Gordon (1982, 1990), Murphy (1999, 2000), and Staiger et al. (1997). Bernanke (2008) provides an overview of several key issues for Phillips curve analyses of inflation.
} 
time variation in the Phillips curve's slope. My analysis is not a formal test of these price-setting models but instead is an assessment of whether the models' implications help improve the ability of the Phillips curve to predict recent inflation. I find that modifying the Phillips curve to allow continuous time-variation in its slope greatly improves its ability to explain the recent behavior of inflation. Unlike Ball and Mazumder (2011), my approach does not rely on anchored expectations to avoid predicting deflation and thus provides an alternative explanation for why inflation has remained above zero.

The paper begins in Section 2 by estimating a standard Phillips curve using data since 1960 and illustrating its prediction of deflation over the past several years, confirming the findings of Ball and Mazumder (2011). I also show that the Phillips curve underpredicts inflation in the years leading up to the Great Recession although it performs very poorly only after 2008. Section 3 explores time variation in the slope of the Phillips curve and confirms that inflation has become much less responsive to economic activity during the past few decades. Estimates of this time variation indicate that the slope of the Phillips curve was close to zero in the years just prior to the Great Recession. I test for an unknown sample breakpoint and find a significant change in slope for the period after the early 1980s and possibly again during the early 1990s. I provide predictions for inflation using Phillips curves estimated on data from only the last few decades, again showing predictions of deflation, albeit less severe than when estimating over the entire sample. But when I simulate Phillips curves using slope estimates from the period of the Great Recession, I find they predict inflation above zero. 
Section 4 considers reasons why the slope of the Phillips curve might vary continuously over time, focusing on implications of the sticky-price and stickyinformation approaches to price adjustment. Under both approaches, uncertainty about market conditions - which I proxy by the variability of inflation and by the dispersion of regional economic conditions - will affect the response of inflation to aggregate demand. Sticky-price models of the type developed by Ball, Mankiw, and Romer (1988) imply a steeper slope when inflation is volatile rather than stable and when regional conditions are varied rather than similar because price setters facing fixed costs of adjusting prices will find it beneficial to change prices more often when uncertainty about aggregate and region-specific shocks is higher. By changing prices more often, these firms are able to keep their price closer to its optimal level. Sticky-information models of the sort presented by Mankiw and Reis (2002) imply a steeper slope when inflation is volatile and regional conditions are varied because price setters will find it beneficial to update information more often and, accordingly, change price paths more often. ${ }^{3}$ Changing price paths more often helps ensure that the firm's price does not deviate too much from its optimal path. The two approaches diverge, however, on how the level of inflation influences the responsiveness of prices to aggregate demand. The sticky-price model predicts more frequent price changes when average inflation is high (holding constant its variability) compared to when it is low. ${ }^{4}$ The sticky-information model, on the other hand, predicts that average inflation has no effect on the frequency of information

\footnotetext{
${ }^{3}$ Reis (2006) shows that the time between information updates depends inversely on uncertainty about a firm's market conditions.

${ }^{4}$ See Ball, Mankiw, and Romer (1988), who present evidence that the slope of the Phillips curve depends on the level of inflation.
} 
updates because the price paths set by firms fully incorporate the average level of inflation.

These implications suggest that the inflation environment and the extent of uncertainty about regional economic conditions should influence the slope of the Phillips curve. I modify the Phillips curve by introducing proxies to account for these effects and find that the model in which the slope to varies with uncertainty about regional conditions can best explain the recent path of inflation. Importantly, this modified Phillips curve predicts that inflation will remain positive without relying on anchored expectations. The paper concludes in Section 5 with a summary of its findings and suggestions for further research.

\section{The Phillips Curve and the Recent Behavior of Inflation}

The standard Phillips curve model relates inflation to expected inflation and the gap between the rate of unemployment and its natural rate:

$$
\pi_{t}=\pi_{t}^{e}+\beta\left[u_{t}-u_{t}^{n}\right]+\varepsilon_{t}
$$

where $\pi$ is the inflation rate, $u$ is the unemployment rate, $u^{n}$ is the natural rate, $\beta<0$, and $\varepsilon$ is an error term that is assumed to be uncorrelated with the gap between unemployment and its natural rate. This identifying assumption treats the disturbance term as capturing relative price movements such as commodity price shocks that are 
assumed to be uncorrelated with the gap variable. ${ }^{5}$ Relationships similar to equation (1)

are consistent with microfounded models based on sticky prices or imperfect

information. ${ }^{6}$

A common approach to estimating equation (1) assumes expected inflation is a function of possibly many lags of past inflation, e.g., Gordon (1982) and Stock and

Watson (2008). I adopt this approach, but limit the lags to four and assume that the coefficients on the lagged inflation terms are equal in magnitude and sum to one so as to preserve the accelerationist feature of the model:

$$
\pi_{t}^{e}=0.25\left[\pi_{t-1}+\pi_{t-2}+\pi_{t-3}+\pi_{t-4}\right]
$$

This formulation implies that a sustained increase in actual inflation will take one year to be fully reflected in expected inflation. ${ }^{7}$ Estimation of equation (1) also requires a measure of the natural rate of unemployment. Following previous authors, I use the estimate of the natural rate produced by the Congressional Budget Office (2013). ${ }^{8}$

Substituting for expected inflation in equation (1) using equation (2) yields:

\footnotetext{
${ }^{5}$ When using core measures of inflation that remove relative price shocks in the food and energy sectors, the identifying assumption is that relative price shocks originating in other sectors are uncorrelated with the gap term.

${ }^{6}$ See, for example, Calvo (1983), Roberts (1995), Lucas (1973), Mankiw and Reis (2002, 2010). The gap variable in Equation (1) is intended to broadly capture fluctuations in marginal cost, which microfounded models imply are a key determinant of movements in inflation. For estimates of Phillips curves using more direct measures of marginal costs, see Mazumder (2010, 2011).

${ }^{7}$ Mankiw, Reis, and Wolfers (2003) find that survey measures of expected inflation are not consistent with either rational expectations or adaptive expectations of the sort used here. They argue that survey measures exhibit some updating in response to recent news about the macroeconomy. I follow the traditional approach to estimating Phillips curve models in maintaining that expected inflation depends on lagged values of actual inflation.

${ }^{8}$ Recently the CBO has provided a two estimates, one of which accounts for temporary labor market conditions that have elevated the natural rate since 2008. I use this CBO "short-run" natural rate in constructing the unemployment gap.
} 


$$
\pi_{t}=0.25\left[\pi_{t-1}+\pi_{t-2}+\pi_{t-3}+\pi_{t-4}\right]+\beta\left[u_{t}-u_{t}^{n}\right]+\varepsilon_{t}
$$

This specification of the Phillips curve captures the accelerationist feature emphasized by Friedman (1968) in that a reduction in unemployment below its natural rate will result in a long-run increase in the rate of inflation. ${ }^{9}$ A variant of this equation uses the gap between actual real GDP and its potential level expressed as a percentage of potential GDP rather than the unemployment gap.

To assess whether a standard Phillips curve can explain the process for inflation following the onset of the Great Recession, I estimate equation (3) for the period up to its start at the end of 2007. I begin my sample in 1960, which has been identified by Barsky (1987) as a breakpoint when inflation changed from a stationary to an integrated, moving average process. ${ }^{10}$

Table 1 presents OLS estimates of equation (3) over the period 1960-2007 using quarterly data for inflation measured using the consumer price index (CPI) and the personal consumption expenditures price index (PCE). I report estimates for both total inflation and inflation less food and energy prices (denoted "core"), and for the GDP gap in addition to the unemployment gap. ${ }^{11}$ In all cases, the coefficient on the gap variable is of the correct sign (negative for the unemployment gap and positive for the GDP gap)

\footnotetext{
${ }^{9}$ By contrast, the New Keynesian Phillips curve implies that inflation is expected to decline when unemployment is below its natural rate, as Roberts (1995) illustrates. I report results for specifications of the New Keynesian Phillips curve in an Appendix to this paper, showing that, like the accelerationist Phillips curve, it also is unable to explain the recent behavior of inflation.

${ }^{10}$ See also Murphy (1986), who discusses a break around 1959 in the process determining inflation expectations as measured by the Livingston expected inflation survey maintained by the Federal Reserve Bank of Philadelphia.

${ }^{11}$ All estimates in this paper use data available as of December 1, 2013, which include the July 2013 Comprehensive Revision of the National Income Accounts by the Bureau of Economic Analysis. Due to changes in methodology, these estimates increased significantly the level of GDP. The Congressional Budget Office has not yet released a comparable potential GDP series, so I use the most recent estimates of the GDP gap provided in February 2013.
} 
and statistically different from zero at high levels of confidence. The restriction that the coefficients on lagged inflation sum to one cannot be rejected.

Figure 1 shows predictions from equation (3) when it is estimated over the period 1960-2007 and then simulated through second quarter of 2013. These dynamic simulations use lagged values of predicted inflation to form the expected inflation variable and actual values of the gap variable. ${ }^{12}$ Figure 1 presents results for core inflation (CPI in panel A and PCE in panel B) with predictions using the two gap series. The inflation rates shown in these figures are four-quarter moving averages, which help smooth out fluctuations in the quarterly data. For both inflation series shown in Figure 1, the model predicts deflation during the last several years regardless of the measure used for the gap variable. Simulations using total inflation (not shown) likewise predict deflation.

As a check on the robustness of these deflation predictions, I extended the estimation sample. Figure 2 shows predictions through the second quarter of 2013 when the estimation sample is 1960 to 2010 . Once again, the model predicts deflation. Results using estimation samples ending in 2008 and 2009 are broadly similar to those shown in Figures 1 and 2, predicting deflation soon after the estimation period ends—-deflation that has not in fact occurred.

Much policy discussion in the early 2000s centered on concern that the U.S. economy was flirting with deflation. ${ }^{13}$ This raises the question of how well the Phillips curve performed over the years leading up to the Great Recession. Figure 3 presents

\footnotetext{
${ }^{12}$ Because the goal of this paper is to assess how well the Phillips curve explains the recent behavior of inflation, I use actual values of the "exogenous" gap variable rather than values for the gap variable that might have been forecast at the end of the estimation period in 2007.

${ }^{13}$ See speeches by Federal Reserve Chair Alan Greenspan (2002) and Federal Reserve Governor Ben Bernanke (2002).
} 
predictions when the estimation sample ends in 2000 and the model is simulated dynamically through second quarter of 2013. As seen in Panel A, the model predicts core CPI inflation reasonably well through 2007 using the GDP gap, although it underpredicts starting in 2004 using the unemployment gap. For core PCE inflation shown in panel B, the model under-predicts starting in 2004 for both measures of the gap. These results indicate that the inflation may have become less sensitive to demand conditions in the years prior to the Great Recession.

\section{A Time-Varying Phillips Curve}

One possible reason for the failure of standard Phillips curve models to explain the recent behavior of inflation is that the slope coefficient on the gap term may vary through time and recently may have become much smaller than the value estimated using data for the past fifty years. Ball and Mazumder (2011) explore this hypothesis by estimating a time-varying parameter model and find support for the view that the slope has declined in recent decades. In this section, I present evidence that confirms a decline in the slope of the Phillips curve using a rolling regression technique. I also test formally for a breakpoint in the relationship and find evidence of a shift in the early 1980s and possibly the early 1990s.

Figure 4 presents estimates of the slope parameter $\beta$ in equation (3) using rolling regressions with 10-year (40-quarter) windows for the period 1960-2013. For both CPI and PCE inflation, the absolute value of the slope parameter is low in the 1960s, rises in the 1970s, declines in the 1980s, and then gradually trends downward through the 1990s, 
falling toward zero in the 2000s. ${ }^{14}$ This pattern qualitatively matches those estimated using more sophisticated time-series techniques, such as in Stock and Watson (2010) or Ball and Mazumder (2011).

Figure 5 shows results of a Quandt Likelihood Ratio test for an unknown structural break in the relationship between inflation and the unemployment gap. ${ }^{15}$ For both core CPI inflation (panel A) and core PCE inflation (panel B) the maximum occurs in the early 1980s and is significant at the one-percent level of confidence. Another smaller peak, significant at the five-percent level, is present in the early 1990s for core CPI inflation, suggesting a second possible breakpoint, although a formal test for the period from 1983 onward (not shown) could not reject the hypothesis of no structural break. Estimates using data from 1983 to 2007, reported in Figure 6, show that the model continues to underpredict inflation, although by substantially less than when estimated for the full sample period.

As Figure 4 illustrates, point estimates of the slope coefficient declined in absolute value during the 2000s, becoming quite small. Figure 7 provides predictions using coefficient estimates from a 40-quarter window centered at the fourth quarter of 2007 (i.e., a sample period of 2003 through 2012). For this in-sample simulation, the model no longer predicts deflation, owing to the attenuated response of inflation to the gap variables. These results suggest that explicitly modeling time-variation of the slope coefficient may help explain the recent behavior of inflation.

\footnotetext{
${ }^{14}$ Results for the GDP gap are similar.

${ }^{15}$ The test involves computing the F-statistic for a Chow test of the null hypothesis of no structural break at each observation over the inner 70 percent of the sample and then choosing the maximum value as the QLR statistic. Confidence levels for the QLR statistic shown in Figure 5 are taken from Table 14.6 in Stock and Watson (2010).
} 
Ball and Mazumder (2011) argue that core inflation is better measured by median CPI inflation than by CPI inflation less food and energy. Their reasoning is that median inflation strips out relative price shocks that originate in more sectors than just food and energy, and hence represents a better measure of "core" inflation. They show that a Phillips curve estimated using median inflation over the more recent 1985-2007 period predicts median inflation reasonably accurately over the following several years. But when they forecast out beyond the end of their sample period in 2010, they predict deflation by 2012. The prediction that deflation is on the way leads Ball and Mazumder (2011) to further modify the Phillips curve by assuming expected inflation is partly anchored to a Federal Reserve target. With this modification, the Phillips curve predicts that inflation will remain positive.

I do not consider median inflation in this paper but focus instead on explaining the behavior of core inflation as measured by the traditional metrics of the CPI less food and energy and the PCE price index less food and energy. My reason for this is two fold. First, these standard measures of inflation are used to frame monetary policy discussions and so seem most relevant for analysts trying to assess potential policy response to economic conditions. ${ }^{16}$ Second, the Phillips curve historically has performed quite well in describing the behavior of these traditional core measures, so it seems sensible to explore whether additional modifications to the model, rather than a change in how we measure core inflation, might help explain the recent behavior. In the next section, I explore a modification to the Phillips curve that improves its ability to predict recent inflation, and do so without relying on anchored expectations.

\footnotetext{
${ }^{16}$ Minutes of the Federal Open Market Committee meetings quite frequently refer to core measures of inflation computed using these traditional metrics.
} 


\section{Explaining Time Variation in the Phillips Curve's Slope}

This section investigates reasons why the Phillips curve's slope may vary through time. I consider implications of price-setting models when prices are costly to adjust and information is costly to obtain. My analysis is not a formal test of these forward-looking price-setting models but instead uses these models' implications to motivate why the Phillips curve's slope may vary with the inflation environment and uncertainty about regional economic conditions.

As shown in Figure 4, the slope coefficient for the Phillips curve declined sharply in absolute value during the late 1970s and early 1980s, and then gradually trended lower in the 1990 s, falling close to zero in the 2000s. This suggests that controlling explicitly for economic conditions that influence the magnitude of the slope coefficient should help improve the predictive performance of the Phillips curve.

In the sticky-price model, firms face fixed costs of adjusting prices and so find it optimal to hold prices constant for some period of time. The frequency with which firms adjust depends on uncertainty about market conditions as well as the average level of inflation. When uncertainty about market conditions is low, the probability also is low that a firm's fixed price will deviate a lot from its optimal value and so firms will hold prices fixed for a longer period of time than when uncertainty is high. Similarly, when the average level of inflation is low, firms will find it optimal to hold prices fixed for a longer period of time because with low inflation it takes longer for the firm's fixed price to deviate from its optimal level. Accordingly, the sticky-price model predicts that the 
response of inflation to slack in the economy varies directly with uncertainty about market conditions and the level of inflation. ${ }^{17}$

By contrast, the sticky-information model assumes prices are costless to change but information about market conditions is costly to acquire. Firms set a path for their prices given current information. ${ }^{18}$ They update their price path only when the perceived benefit of acquiring information exceeds its cost. Greater uncertainty about market conditions, and hence greater uncertainty about whether a firm's price path is out of line with competitors, will increase the perceived benefit of acquiring information and lead to more frequent updating. Thus, the sticky-information model also predicts that the slope of the Phillips curve will vary over time with changes in uncertainty about a firm's market conditions. ${ }^{19}$ But unlike the sticky-price model, the sticky-information model predicts that the average level of inflation has no effect on the responsiveness of prices to aggregate demand. The reason for this is that inflation has no effect on the frequency of information updates because price paths set by firms fully incorporate the average level of inflation.

I assume that uncertainty about market conditions can be approximated by uncertainty about inflation (measured using the standard deviation of inflation) and by uncertainty about regional economic conditions. As a proxy for uncertainty about regional economic conditions, I use the standard deviation of growth in state personal income relative to growth in national personal income. The growth rate is computed as

\footnotetext{
${ }^{17}$ See Ball, Mankiw, and Romer (1988) for a discussion of the sticky-price model's implications for the slope of the Phillips curve.

${ }^{18}$ See Mankiw and Reis $(2007,2010)$ for overviews of price-setting models in which information is imperfect.

${ }^{19}$ Reis (2006) shows that greater uncertainty about a firm's market conditions reduces the time between information updates, thereby increasing the responsiveness of prices and inflation to aggregate demand.
} 
the percent change over the same quarter a year ago. I calculate the standard deviation for each quarter using data for all fifty states.

Figure 8 shows this regional dispersion variable, computed as a four-quarter moving average to smooth out quarterly volatility. The dispersion measure is relatively low in the 1960s, rises sharply and becomes more volatile in the 1970s, and then declines and becomes less volatile from the mid-1980s onward. This pattern broadly matches the estimates of time-variation in the slope coefficient of the Phillips curve shown earlier in Figure 4.

Figure 9 plots the mean and standard deviation of inflation, computed on a rolling basis over 40 -quarter intervals. ${ }^{20}$ These measures of the inflation environment are low in the 1960s, increase in the 1970s, decline in the 1980s through the 1990s, and remain low in the 2000s. This pattern likewise qualitatively matches the time-variation in the slope coefficient of the Phillips curve, although both of the inflation series exhibit much less volatility than the regional dispersion series.

To assess whether accounting for the inflation environment and/or regional dispersion in economic conditions improves the ability of the Phillips curve to explain recent inflation, I modify equation (3) to allow the slope coefficient to vary over time. In particular, I estimate variants of the following equation:

$$
\begin{aligned}
\pi_{t}=0.25\left[\pi_{t-1}+\pi_{t-2}+\pi_{t-3}+\pi_{t-4}\right]+\beta_{0}\left[u_{t}-u_{t}^{n}\right] \\
+\beta_{1} \bar{\pi}_{t}\left[u_{t}-u_{t}^{n}\right]+\beta_{2} \sigma_{t}^{\pi}\left[u_{t}-u_{t}^{n}\right]+\beta_{3} \sigma_{t}^{y}\left[u_{t}-u_{t}^{n}\right]
\end{aligned}
$$

\footnotetext{
${ }^{20}$ The rolling estimates are centered at the midpoint of the 40-quarter windows. I fill out the first and last 20 quarters using the estimates from the first and last 40 -quarter windows.
} 
where $\bar{\pi}_{t}$ and $\sigma_{t}^{\pi}$ are four-quarter moving averages of the mean and standard deviation of inflation, and $\sigma_{t}^{y}$ is the four-quarter moving average of the standard deviation of quarterly state personal income growth around national personal income growth. The interaction terms capture variation in the slope coefficient over time. ${ }^{21}$

Table 2 reports estimates of two variants of equation (4), first reproducing the earlier results without interaction terms, denoted (a) in the table, and then providing estimates including the inflation environment terms, $\bar{\pi}_{t}$ and $\sigma_{t}^{\pi}$, denoted (b). I provide estimates for the period 1960 to 2007 and for the period 1960 through the second quarter of 2013. ${ }^{22}$ The coefficients on the inflation environment terms $\left(\beta_{1}\right.$ and $\left.\beta_{2}\right)$ are each statistically significant at the five-percent level for estimates using core CPI inflation, although the coefficient on the inflation variance term $\left(\beta_{2}\right)$ has an incorrect (positive) sign. For core PCE inflation, the coefficients are only jointly, not individually, significant and the coefficient on the inflation variance term again has an incorrect (positive) sign. A high degree of collinearity between $\bar{\pi}_{t}$ and $\sigma_{t}^{\pi}$ apparently makes the individual effects hard to distinguish — when the mean of inflation, $\bar{\pi}_{t}$, is entered alone (second column under variant (b)), its coefficient is always statistically significant and of the correct sign. ${ }^{23}$ These results provide only weak support for the sticky-price model's implication that the average level of inflation influences the slope of the Phillips curve,

\footnotetext{
${ }^{21}$ This specification of the Phillips curve allows the slope coefficient to vary with the inflation environment and uncertainty about regional economic conditions. The equation is not intended to be a representation of the Mankiw and Reis (2002) sticky-information Phillips curve or the sticky-price New Keynesian Phillips curve. I use those frameworks only to motivate in a general sense why the slope coefficient might vary over time.

${ }^{22}$ In the interests of brevity, I only show estimates for specifications using the unemployment gap in Tables 2 and 3 . Estimates using the GDP gap are qualitatively similar.

${ }^{23}$ When the variance of inflation variance term is entered alone (not shown), its coefficient is not significant.
} 
while the positive coefficient on the variance term is at odds with implications of both the sticky price and sticky information approaches to price setting.

Table 3 reports estimates for two variants of equation (4) that include the regional dispersion term, $\sigma_{t}^{y}$. I present results for the dispersion term alone, denoted (c) in the table, and in combination with the inflation environment terms, denoted (d). As before, I provide estimates for the period 1960 to 2007 and for the period 1960 through the second quarter of 2013. The coefficient on the regional dispersion term $\left(\beta_{3}\right)$ is statistically significant at the one-percent level in all specifications, and has the correct (negative) sign. When I include both the dispersion term and the inflation environment terms (first column under variant $(\mathrm{d}))$, the coefficients on the latter $\left(\beta_{1}\right.$ and $\left.\beta_{2}\right)$ are statistically significant at the five-percent level for core CPI inflation, although the coefficient on the inflation variance term $\left(\beta_{2}\right)$ again has an incorrect (positive) sign. For estimates using core PCE inflation, the coefficients on the inflation terms are not statistically significant, either individually or jointly. Interestingly, when the mean of inflation term, $\bar{\pi}_{t}$, alone is included with the regional dispersion term (second column under variant (d)), its coefficient is never statistically significant, while the coefficient on the dispersion term always has the correct (negative) sign, is statistically significant, and stable across specifications. $^{24}$

The results in Tables 2 and 3 indicate that time variation in the slope of the Phillips curve is more closely related to regional dispersion of income growth than to the inflation environment. I interpret this as suggesting that uncertainty about regional

\footnotetext{
${ }^{24}$ When the inflation variance term alone is included with the regional dispersion term (not shown), its coefficient is never statistically significant, while the coefficient on the regional dispersion term is negative and significant.
} 
economic conditions, as measured by the regional dispersion of income growth, helps explain time variation in the slope of the Phillips curve. As discussed earlier, the average level of inflation should affect the slope of the Phillips curve in the sticky-price model but not the sticky-information model. Because the interaction term for the mean of inflation loses significance when combined with the regional dispersion term, the results seem more supportive of the sticky-information approach, although uncertainty about regional economic conditions certainly should also matter for firms setting prices under the sticky-price approach.

Given that these interaction terms find some statistical support, I repeat the earlier exercise of predicting recent inflation but now use variants (c) and (d) reported in Table 3 in which the slope varies continuously. As before, I estimate the model over the period 1960 to 2007 and then dynamically forecast inflation through the second quarter of 2013. I also estimate the model over the period 1960 to 2000 and forecast inflation through the second quarter of 2013 as a check on whether either variant can explain inflation during the early 2000s.

Figure 10 presents predictions for the model estimated through 2007. For both measures of core inflation, the specification that allows the slope to vary with the regional dispersion term (variant (c)) performs best, tracking inflation closely for the PCE measure and somewhat less well for the CPI measure. By contrast, when interaction terms for the inflation environment are added to the model (first column under variant (d)), core inflation is predicted to trend steadily downward and become increasingly negative, similar to the model with a constant slope. Figure 11 provides predictions for the model when it is estimated only through 2000 . Here the specification that allows the 
slope to vary with the regional dispersion term performs reasonably well in tracking both measures of inflation closely over the subsequent thirteen years.

To assess the statistical significance of these predictions, Figure 12 reports 90 percent confidence bands around quarterly predictions of inflation for the specification that allows the slope to vary with the regional dispersion term and the specification that maintains a constant slope. The model is estimated over the period 1960 to 2000 and then used to predict inflation through the second quarter of 2013. Although predictions for the variant that includes the regional dispersion term have a lower confidence band containing negative values for inflation (top charts in Figure 12), the predictions and the upper confidence band remain above zero through the end of the forecast period. This contrasts sharply with the statistically significant prediction of a descent into deflation for the model with a constant slope coefficient (bottom charts in Figure 12), where the confidence bands contain only negative values for inflation from 2010 onward. ${ }^{25}$ Overall, these results indicate that time variation in the slope of the Phillips curve as captured by time variation in the regional dispersion of economic conditions can help explain the recent behavior of inflation.

\section{Summary}

This paper considers whether the Phillips curve can explain the recent behavior of inflation in the United States. Standard formulations of the model indicate that the continuing large shortfall in economic activity relative to full employment should have led to deflation over the past several years. As in Ball and Mazumder (2011), I find

\footnotetext{
${ }^{25}$ Confidence bands for forecasts using specifications that include the inflation interaction terms (not shown) similarly find a statistically significant descent into deflation.
} 
evidence that the slope of the Phillips curve has varied over time and probably is lower today than it was several decades ago. This implies that estimates of Phillips curves using historical data will overstate the responsiveness of inflation to present-day economic conditions.

Estimates of the Phillips curve that use data only from the past three decades show a reduced response of inflation to economic slack, but simulations of these models continue to predict deflation for recent years. One possibility for why inflation has remained above zero is that the Federal Reserve is viewed as being committed to a positive inflation target and this commitment has the effect of anchoring expectations about future inflation. ${ }^{26}$ If this has indeed been the case, a key question arises as to exactly how long such anchoring can keep inflation above zero in the face of persistent economic slack.

I instead consider whether modifying the Phillips curve to explicitly account for time variation in its slope coefficient can explain the recent behavior of inflation without relying on anchored expectations. I explore reasons for why the slope of the Phillips curve might vary over time, focusing on implications of the sticky-price and stickyinformation approaches to price adjustment. These implications suggest that the inflation environment and the extent of uncertainty about regional economic conditions should influence the slope of the Phillips curve. I modify the Phillips curve by introducing proxies to account for these effects and find that the dispersion of regional economic activity is helpful for explaining the recent path of inflation.

\footnotetext{
${ }^{26}$ See Bernanke (2010) and Williams (2010) as cited in Ball and Mazumder (2011). For additional discussion on anchoring of inflation expectations, see Williams (2006).
} 
Future research should explore formal implications of the sticky-price and stickyinformation models for time-variation in the slope of the Phillips curve. In particular, state-dependent versions of the sticky-price and sticky-information models could provide frameworks to directly test the intuitive notion used in this paper that the timing of price adjustment and information acquisition is endogenous. Other proxies for uncertainty about regional economic conditions also could be investigated and tested in the Phillips curve framework. Finally, future research should document whether the traditional Phillips curve model has failed to explain recent inflation in other countries. 


\section{Appendix: The New Keynesian Phillips Curve}

As derived by Roberts (1995), a basic version of the sticky-price New Keynesian Phillips curve expresses current inflation as a function of the rate of inflation expected for next period and the gap between unemployment and its natural rate (or alternatively, the output gap):
(A.1)

$$
\pi_{t}=E_{t} \pi_{t+1}+\beta\left[u_{t}-u_{t}^{n}\right]+\varepsilon_{t}
$$

where $\beta<0$ ( $\beta>0$ for the output gap), and $\varepsilon$ is an error term. The gap variable is intended to capture movements in marginal cost that influence price setting behavior by firms.

Table A1 provides estimates of equation (A.1) using the generalized method of moments applied to the following orthogonality condition:

$$
E_{t}\left\{\left(\pi_{t}-\beta\left[u_{t}-u_{t}^{n}\right]-\pi_{t+1}\right) \mathbf{z}_{t}^{\prime}\right\}=0
$$

where the $z_{t}^{\prime}$ is a vector of instruments containing eight lags each of inflation, the unemployment gap, and the output gap. I employ the same gap variables used in Table 1 of the text for comparability with those results and because standard measures of marginal cost based on labor share have been shown by Mazumder $(2010,2011)$ to be poor proxies for marginal cost faced by firms.

As seen in Table A1, the coefficient on the gap variables is statistically significant at the five-percent level for both core PCE and core CPI inflation over the period 1960 to 
2007, but of the incorrect sign rejecting the specification of equation (A.1). For the period 1960 into 2013, the estimate for core PCE inflation is statistically significant while those for core CPI inflation is only weakly significant (ten-percent level), but again the coefficient has the wrong sign. These results are consistent with Mankiw (2001), Ball and Mazumder (2011), and other authors who demonstrate the poor performance of this specification of the Phillips curve. The results indicate that slack in the economy is associated with an expected decline in inflation, not the increase implied by the New Keynesian Phillips curve.

Figure 1A shows the four-quarter moving average of the predictions from equation (A.1) when it is estimated over the period 1960 to 2007 and then simulated through second quarter of 2013. The model does poorly and predicts a sharp decent into deflation, similar to results using the traditional backward-looking Phillips curve illustrated in Figure 1 of the text. 


\section{References}

Ball, L., N. Mankiw, and D. Romer (1988): "The New Keynsesian Economics and the Output-Inflation Trade-off," Brookings Papers on Economic Activity, 19, 1-82.

Ball, L. and S. Mazumder (2011): "Inflation Dynamics and the Great Recession," Brookings Papers on Economic Activity, Spring 2011, 337-381.

Barsky, R. (1987): "The Fisher Hypothesis and the Forecastability and Persistence of Inflation," Journal of Monetary Economics, 19, 3-24.

Bernanke, B. (2002): “Deflation: Making Sure “It” Doesn't Happen Here,” Remarks before the National Economists Club, Washington, DC, November 21, 2002.

Bernanke, B. (2008): “Outstanding Issues in the Analysis of Inflation," in Understanding Inflation and the Implications for Monetary Policy, ed. by J. Fuhrer, Y. Kodrzycki, J. Little and G. Olivei, MIT Press, 447-456.

Bernanke, B. (2010): "The Economic Outlook and Monetary Policy," Speech at the Federal Reserve Bank of Kansas City Economic Symposium, Jackson Hole, Wyoming.

Calvo, G. (1983): "Staggered Prices in a Utility Maximizing Framework," Journal of Monetary Economics, 12, 383-398.

Congressional Budget Office (2013): "The Budget and Economic Outlook: Fiscal Years 2013 to 2023," February 2013, Washington, DC.

Friedman, M. (1968): “The Role of Monetary Policy," American Economic Review, 58, $1-17$.

Fuhrer, J. (1995): “The Phillips Curve is Alive and Well," New England Economic Review, March/April, 41-56.

Gordon, R. (1982): "Inflation, Flexible Exchange Rates, and the Natural Rate of Unemployment," in Workers, Jobs, and Inflation, ed. by M. Baily, The Brookings Institution, 89-158.

Gordon, R. (1990): “U.S. Inflation, Labor's Share, and the Natural Rate of Unemployment," in Economics of Wage Determination, ed. by H. Koenig, Berlin: Springer-Verlag. 
Greenspan, A. (2002): "Issues for Monetary Policy," Remarks before the Economic Club of New York, New York City, December 19, 2002.

Lucas, R. (1973): "Some International Evidence on Output-Inflation Tradeoffs," American Economic Review, 63, 326-34.

Mankiw, N. (2001): "The Inexorable and Mysterious Tradeoff Between Inflation and Unemployment," Economic Journal, 111, C45-C61.

Mankiw, N. and R. Reis (2002): "Sticky Information Versus Sticky Price: A Proposal to Replace the New Keynesian Phillips Curve," Quarterly Journal of Economics, 117, $1295-1328$.

Mankiw, N. and R. Reis (2007): "Sticky Information in General Equilibrium," Journal of the European Economic Association, 2, 603-13.

Mankiw, N. and R. Reis (2010): "Chapter 5 - Imperfect Information and Aggregate Supply," in Handbook of Monetary Economics, ed. by B. Friedman and M. Woodford, Elsevier, Volume 3, 183-229.

Mankiw, N., R. Reis, and J. Wolfers (2003): "Disagreement about Inflation Expectations,” NBER Working Paper \#9796, June 2003.

Mazumder, S. (2010): "The New Keynesian Phillips Curve and the Cyclicality of Marginal Cost," Journal of Macroeconomics, 32, 747-65.

Mazumder, S. (2011): “Cost-based Phillips Curve Forecasts of Inflation," Journal of Macroeconomics, 33, 553-67.

Murphy, R. (1986): "The Expectations Theory of the Term Structure: Evidence from Inflation Forecasts," Journal of Macroeconomics, 8, 423-34.

Murphy, R. (1999): “Accounting for the Recent Decline in the NAIRU," Business Economics, Volume 34.

Murphy, R. (2000): “What's Behind the Decline in the NAIRU?" in The Economic Outlook For 2000, ed. by S. Hymans, University of Michigan, January 2000.

Reinhart, C. and K. Rogoff (2009): This Time Is Different: Eight Centuries of Financial Folly, Princeton University Press. 
Reis, R. (2006): “Inattentive Producers,” Review of Economic Studies, 73, 793-821.

Roberts, J. (1995): "New Keynesian Economics and the Phillips Curve," Journal of Money, Credit, and Banking, 27, 975-984.

Staiger, D., J. Stock, and M. Watson (1997): "How Precise Are Estimates of the Natural Rate of Unemployment?" in Reducing Inflation: Motivation and Strategy, NBER, 195246.

Stock, J. and M. Watson (2008): "Phillips Curve Inflation Forecasts," NBER Working Paper, 14322.

Stock, J. and M. Watson (2010): “Modeling Inflation After the Crisis," NBER Working Paper, 16488.

Stock, J. and M. Watson (2010): Introduction to Econometrics, Prentice Hall.

Williams, J. (2006): "Inflation Persistence in an Era of Well-anchored Inflation Expectations," FRBSF Economic Letter, 2006-27.

Williams, J. (2010): "Sailing into Headwinds: The Uncertain Outlook for the U.S. Economy," Presentation to Joint Meeting of the San Francisco and Salt Lake City Branch Boards of Directors, Salt Lake City, UT. 
Table 1: Phillips Curve Estimates for Sample Period 1960:1 to 2007:4

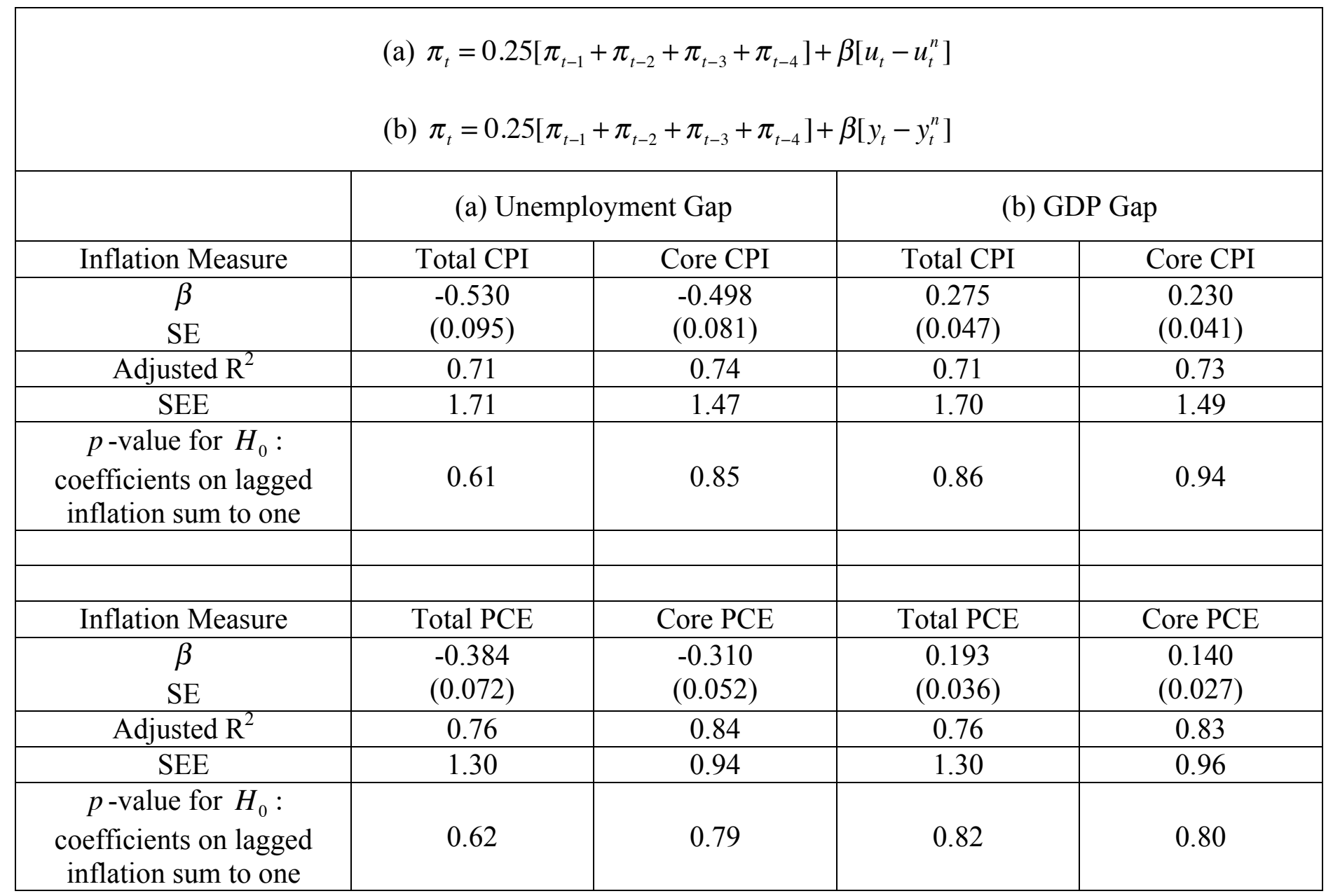

Note: $\pi_{t}$ is the inflation rate, $u_{t}$ is the unemployment rate, $u_{t}^{*}$ is the CBO estimate of the natural rate of unemployment, $y_{t}$ is the log of real GDP, and $y_{t}^{n}$ is the log of the CBO estimate of potential real GDP. Estimation technique is OLS. 
Table 2: Phillips Curve Estimates with Level and Variance of Inflation Sample Periods: 1960:1 to $2007: 4$ and 1960:1 to $2013: 2$

\begin{tabular}{|c|c|c|c|c|c|c|}
\hline \multicolumn{7}{|c|}{ (a) $\pi_{t}=0.25\left[\pi_{t-1}+\pi_{t-2}+\pi_{t-3}+\pi_{t-4}\right]+\beta_{0}\left[u_{t}-u_{t}^{n}\right]$} \\
\hline \multirow[b]{2}{*}{ Inflation Measure } & \multicolumn{6}{|c|}{ Sample Period 1960:1 to $2007: 4$} \\
\hline & \multicolumn{3}{|c|}{ Core CPI } & \multicolumn{3}{|c|}{ Core PCE } \\
\hline & Equation (a) & \multicolumn{2}{|c|}{ Equation (b) } & Equation (a) & \multicolumn{2}{|c|}{ Equation (b) } \\
\hline $\begin{array}{l}\beta_{0} \\
\mathrm{SE}\end{array}$ & $\begin{array}{l}-0.498 \\
(0.081)\end{array}$ & $\begin{array}{c}0.222 \\
(0.245)\end{array}$ & $\begin{array}{c}0.177 \\
(0.247)\end{array}$ & $\begin{array}{l}-0.310 \\
(0.052)\end{array}$ & $\begin{array}{l}-0.001 \\
(0.178)\end{array}$ & $\begin{array}{c}0.044 \\
(0.159)\end{array}$ \\
\hline $\begin{array}{c}\beta_{1} \\
\mathrm{SE}\end{array}$ & & $\begin{array}{l}-0.349 \\
(0.106)\end{array}$ & $\begin{array}{l}-0.127 \\
(0.044)\end{array}$ & & $\begin{array}{l}-0.112 \\
(0.071)\end{array}$ & $\begin{array}{l}-0.077 \\
(0.033)\end{array}$ \\
\hline $\begin{array}{l}\beta_{2} \\
\mathrm{SE}\end{array}$ & & $\begin{array}{c}0.441 \\
(0.193)\end{array}$ & & & $\begin{array}{c}0.116 \\
(0.209)\end{array}$ & \\
\hline Adjusted $\mathrm{R}^{2}$ & 0.74 & 0.76 & 0.75 & 0.84 & 0.84 & 0.84 \\
\hline SEE & 1.47 & 1.42 & 1.44 & 0.94 & 0.93 & 0.94 \\
\hline$p$-value for $H_{0}: \beta_{1}=\beta_{2}=0$ & & 0.00 & & & 0.06 & \\
\hline & \multicolumn{6}{|c|}{ Sample Period 1960:1 to 2013:2 } \\
\hline \multirow[t]{2}{*}{ Inflation Measure } & \multicolumn{3}{|c|}{ Core CPI } & \multicolumn{3}{|c|}{ Core PCE } \\
\hline & Equation (a) & \multicolumn{2}{|c|}{ Equation (b) } & Equation (a) & \multicolumn{2}{|c|}{ Equation (b) } \\
\hline $\begin{array}{l}\beta_{0} \\
\mathrm{SE}\end{array}$ & $\begin{array}{l}-0.326 \\
(0.064)\end{array}$ & $\begin{array}{c}0.346 \\
(0.140)\end{array}$ & $\begin{array}{c}0.225 \\
(0.131)\end{array}$ & $\begin{array}{l}-0.203 \\
(0.042)\end{array}$ & $\begin{array}{c}0.120 \\
(0.089)\end{array}$ & $\begin{array}{c}0.125 \\
(0.087)\end{array}$ \\
\hline $\begin{array}{l}\beta_{1} \\
\mathrm{SE}\end{array}$ & & $\begin{array}{l}-0.358 \\
(0.101)\end{array}$ & $\begin{array}{l}-0.135 \\
(0.028)\end{array}$ & & $\begin{array}{l}-0.109 \\
(0.070)\end{array}$ & $\begin{array}{l}-0.092 \\
(0.022)\end{array}$ \\
\hline $\begin{array}{l}\beta_{2} \\
\mathrm{SE}\end{array}$ & & $\begin{array}{c}0.419 \\
(0.183)\end{array}$ & & & $\begin{array}{c}0.048 \\
(0.185)\end{array}$ & \\
\hline Adjusted $\mathrm{R}^{2}$ & 0.74 & 0.77 & 0.76 & 0.83 & 0.85 & 0.85 \\
\hline SEE & 1.45 & 1.37 & 1.38 & 0.94 & 0.91 & 0.91 \\
\hline$p$-value for $H_{0}: \beta_{1}=\beta_{2}=0$ & & 0.00 & & & 0.00 & \\
\hline
\end{tabular}

Note: $\pi_{t}$ is the inflation rate, $u_{t}$ is the unemployment rate, $u_{t}^{*}$ is the CBO estimate of the short-run natural rate of unemployment, and $\bar{\pi}_{t}$ and $\sigma_{t}^{\pi}$ are four-quarter moving averages of the mean and standard deviation of inflation calculated on a rolling basis over the sample period. Estimation technique is OLS. 
Table 3: Phillips Curve Estimates with Dispersion of Regional Income Growth Sample Periods: 1960:1 to $2007: 4$ and 1960:1 to $2013: 2$

\begin{tabular}{|c|c|c|c|c|c|c|}
\hline \multicolumn{7}{|c|}{$\begin{array}{c}\text { (c) } \pi_{t}=0.25\left[\pi_{t-1}+\pi_{t-2}+\pi_{t-3}+\pi_{t-4}\right]+\beta_{0}\left[u_{t}-u_{t}^{n}\right]+\beta_{3} \sigma_{t}^{y}\left[u_{t}-u_{t}^{n}\right] \\
\text { (d) } \pi_{t}=0.25\left[\pi_{t-1}+\pi_{t-2}+\pi_{t-3}+\pi_{t-4}\right]+\beta_{0}\left[u_{t}-u_{t}^{n}\right]+\beta_{1} \bar{\pi}_{t}\left[u_{t}-u_{t}^{n}\right]+\beta_{2} \sigma_{t}^{\pi}\left[u_{t}-u_{t}^{n}\right]+\beta_{3} \sigma_{t}^{y}\left[u_{t}-u_{t}^{n}\right]\end{array}$} \\
\hline & \multicolumn{6}{|c|}{ Sample Period 1960:1 to $2007: 4$} \\
\hline Inflation Measure & \multicolumn{3}{|c|}{ Core CPI } & \multicolumn{3}{|c|}{ Core PCE } \\
\hline & Equation (c) & \multicolumn{2}{|c|}{ Equation (d) } & Equation (c) & \multicolumn{2}{|c|}{ Equation (d) } \\
\hline $\begin{array}{l}\beta_{0} \\
\mathrm{SE}\end{array}$ & $\begin{array}{c}0.597 \\
(0.241)\end{array}$ & $\begin{array}{c}0.660 \\
(0.261)\end{array}$ & $\begin{array}{c}0.594 \\
(0.264)\end{array}$ & $\begin{array}{c}0.454 \\
(0.153)\end{array}$ & $\begin{array}{c}0.290 \\
(0.178)\end{array}$ & $\begin{array}{c}0.364 \\
(0.163)\end{array}$ \\
\hline $\begin{array}{l}\beta_{1} \\
\mathrm{SE}\end{array}$ & & $\begin{array}{l}-0.237 \\
(0.106)\end{array}$ & $\begin{array}{c}0.001 \\
(0.055)\end{array}$ & & $\begin{array}{c}0.003 \\
(0.071)\end{array}$ & $\begin{array}{c}0.064 \\
(0.042)\end{array}$ \\
\hline $\begin{array}{l}\beta_{2} \\
\mathrm{SE}\end{array}$ & & $\begin{array}{c}0.485 \\
(0.187)\end{array}$ & & & $\begin{array}{c}0.210 \\
(0.198)\end{array}$ & \\
\hline $\begin{array}{l}\beta_{3} \\
\mathrm{SE}\end{array}$ & $\begin{array}{l}-0.334 \\
(0.070)\end{array}$ & $\begin{array}{l}-0.349 \\
(0.089)\end{array}$ & $\begin{array}{l}-0.335 \\
(0.090)\end{array}$ & $\begin{array}{l}-0.233 \\
(0.044)\end{array}$ & $\begin{array}{l}-0.301 \\
(0.060)\end{array}$ & $\begin{array}{l}-0.295 \\
(0.060)\end{array}$ \\
\hline Adjusted $\mathrm{R}^{2}$ & 0.77 & 0.78 & 0.77 & 0.86 & 0.86 & 0.86 \\
\hline SEE & 1.39 & 1.37 & 1.39 & 0.88 & 0.88 & 0.88 \\
\hline$p$-value for $H_{0}: \beta_{1}=\beta_{2}=0$ & & 0.04 & & & 0.18 & \\
\hline & \multicolumn{6}{|c|}{ Sample Period 1960:1 to 2013:2 } \\
\hline Inflation Measure & \multicolumn{3}{|c|}{ Core CPI } & \multicolumn{3}{|c|}{ Core PCE } \\
\hline & Equation (c) & \multicolumn{2}{|c|}{ Equation (d) } & Equation (c) & \multicolumn{2}{|c|}{ Equation $(\mathrm{d})$} \\
\hline $\begin{array}{l}\beta_{0} \\
\mathrm{SE}\end{array}$ & $\begin{array}{c}0.693 \\
(0.172)\end{array}$ & $\begin{array}{c}0.832 \\
(0.179)\end{array}$ & $\begin{array}{c}0.688 \\
(0.172)\end{array}$ & $\begin{array}{c}0.487 \\
(0.111)\end{array}$ & $\begin{array}{c}0.493 \\
(0.112)\end{array}$ & $\begin{array}{c}0.498 \\
(0.111)\end{array}$ \\
\hline $\begin{array}{l}\beta_{1} \\
\mathrm{SE}\end{array}$ & & $\begin{array}{l}-0.253 \\
(0.101)\end{array}$ & $\begin{array}{l}-0.016 \\
(0.041)\end{array}$ & & $\begin{array}{c}0.005 \\
(0.070)\end{array}$ & $\begin{array}{c}0.033 \\
(0.032) \\
\end{array}$ \\
\hline $\begin{array}{l}\beta_{2} \\
\text { SE }\end{array}$ & & $\begin{array}{c}0.453 \\
(0.180)\end{array}$ & & & $\begin{array}{c}0.081 \\
(0.175)\end{array}$ & \\
\hline $\begin{array}{l}\beta_{3} \\
\mathrm{SE}\end{array}$ & $\begin{array}{l}-0.356 \\
(0.056)\end{array}$ & $\begin{array}{l}-0.341 \\
(0.083)\end{array}$ & $\begin{array}{l}-0.331 \\
(0.084)\end{array}$ & $\begin{array}{l}-0.241 \\
(0.036)\end{array}$ & $\begin{array}{l}-0.287 \\
(0.057)\end{array}$ & $\begin{array}{c}-0.286 \\
(0.057)\end{array}$ \\
\hline Adjusted $\mathrm{R}^{2}$ & 0.78 & 0.79 & 0.78 & 0.86 & 0.86 & 0.86 \\
\hline SEE & 1.33 & 1.32 & 1.34 & 0.86 & 0.86 & 0.86 \\
\hline$p$-value for $H_{0}: \beta_{1}=\beta_{2}=0$ & & 0.04 & & & 0.53 & \\
\hline
\end{tabular}

Note: $\pi_{t}$ is the inflation rate, $u_{t}$ is the unemployment rate, $u_{t}^{*}$ is the CBO estimate of the short-run natural rate of unemployment, $\sigma_{t}^{y}$ is the four-quarter moving average of the standard deviation of quarterly state personal income growth around national personal income growth, and $\bar{\pi}_{t}$ and $\sigma_{t}^{\pi}$ are four-quarter moving averages of the mean and standard deviation of inflation calculated on a rolling basis over the sample period. Estimation technique is OLS. 
Table A1: New Keynesian Phillips Curve Estimates

Sample Period: $1960: 1$ to $2007: 4$ and 1960:1 to $2013: 2$

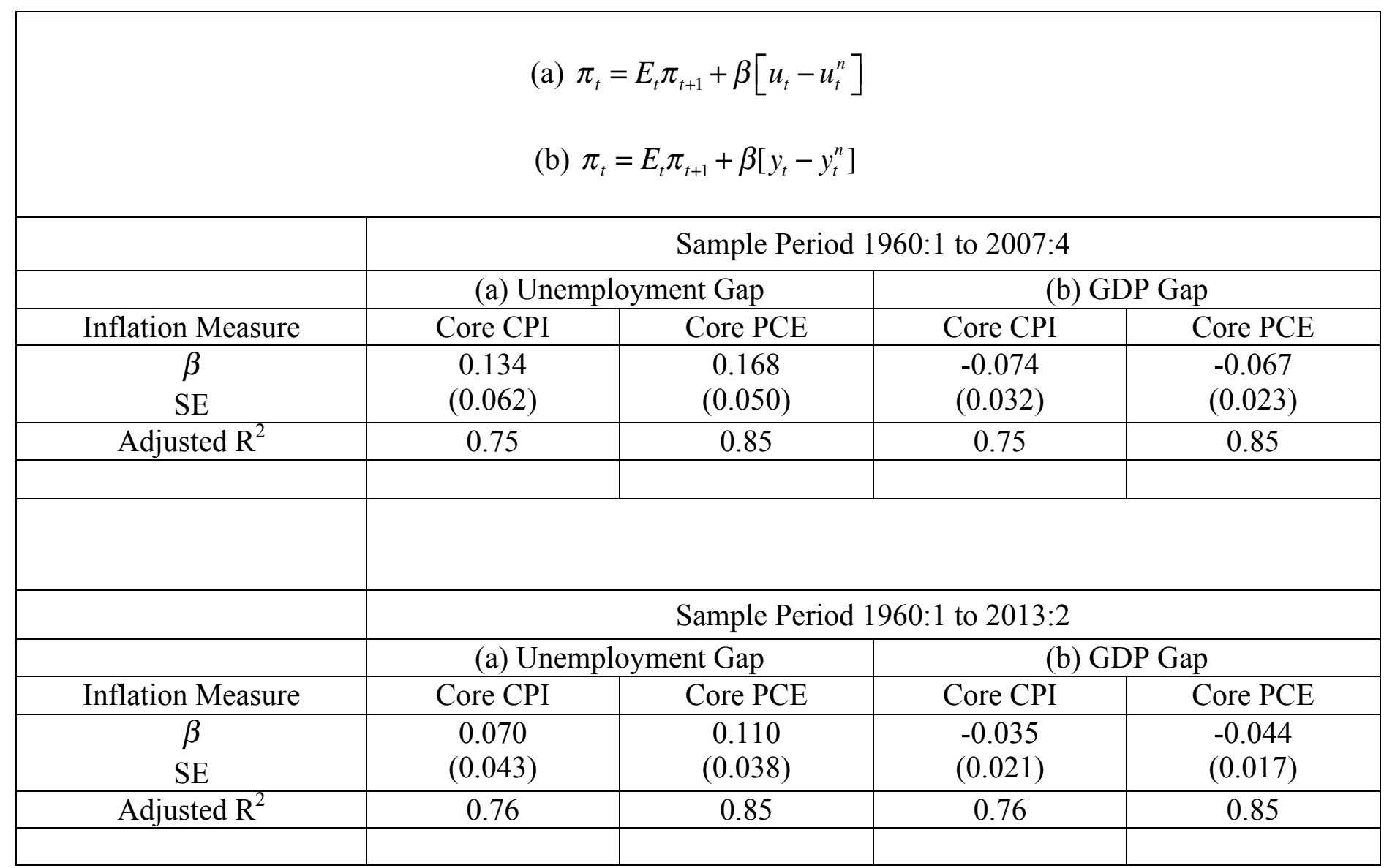

Note: $\pi_{t}$ is the inflation rate, $u_{t}$ is the unemployment rate, $u_{t}^{*}$ is the CBO estimate of the natural rate of unemployment, $y_{t}$ is the log of real GDP, and $y_{t}^{n}$ is the log of the CBO estimate of potential real GDP. Estimation technique is generalized method of moments using eight lags each of inflation, the unemployment gap, and the output gap as instruments. 
Figure 1: Dynamic Predictions of Inflation for 2008:1-2013:2 Using 1960:1-2007:4 Sample Period 4-Quarter Moving Average

(A) Core CPI Inflation

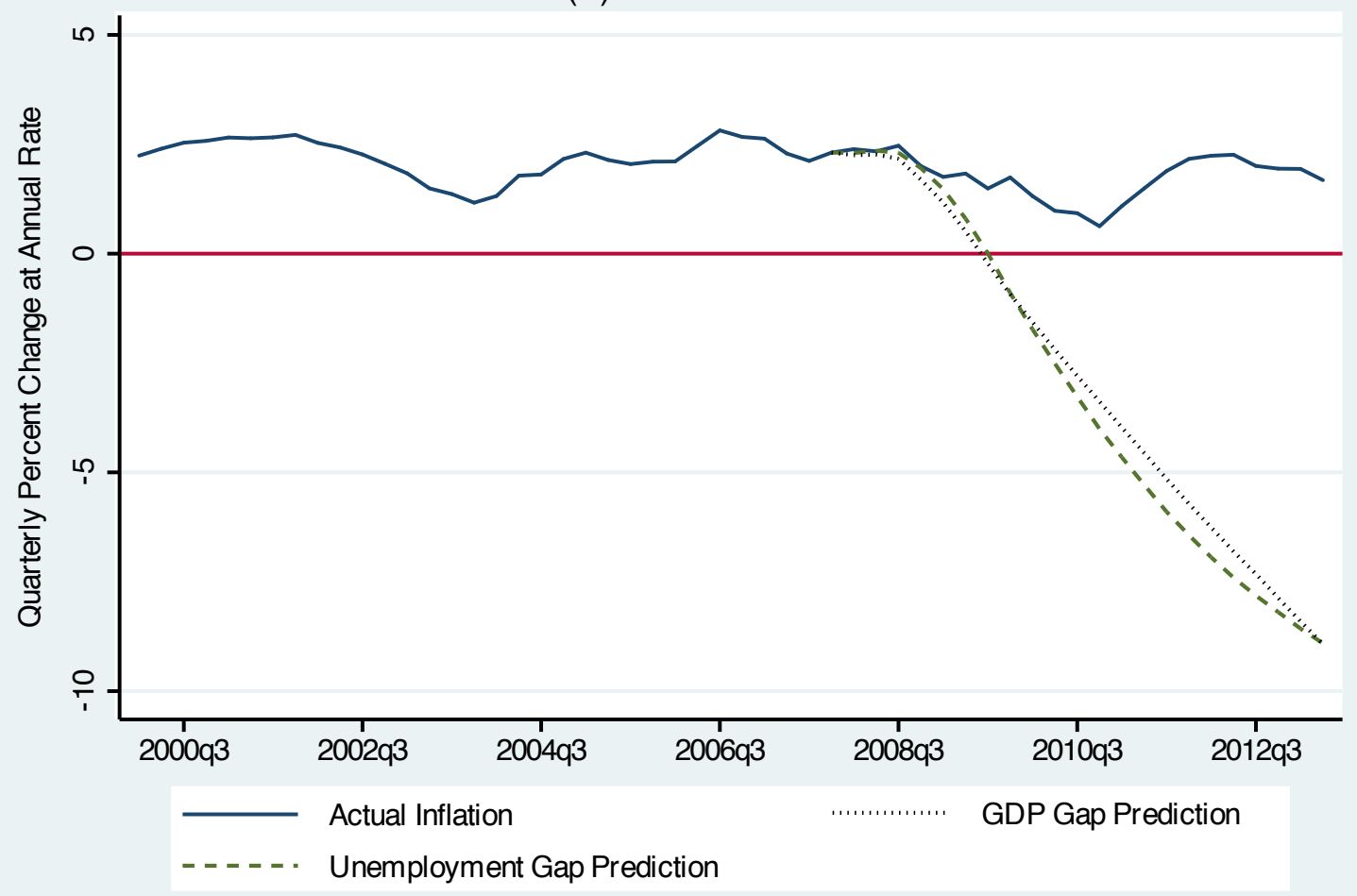

(B) Core PCE Inflation

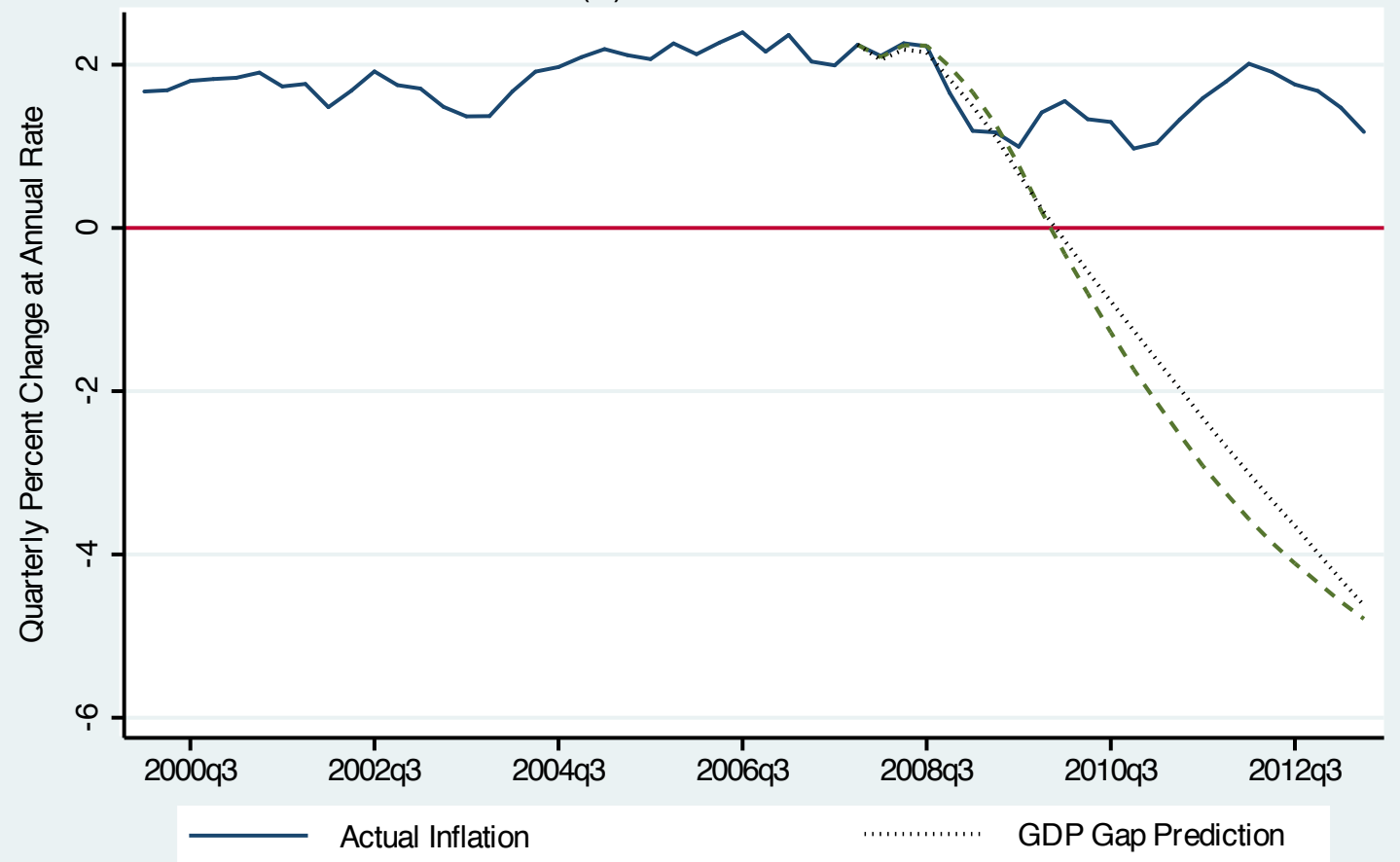

- - - - - . Unemployment Gap Prediction 
Figure 2: Dynamic Predictions of Inflation for 2011:1-2013:2 Using 1960:1-2010:4 Sample Period 4-Quarter Moving Average

(A) Core CPI Inflation

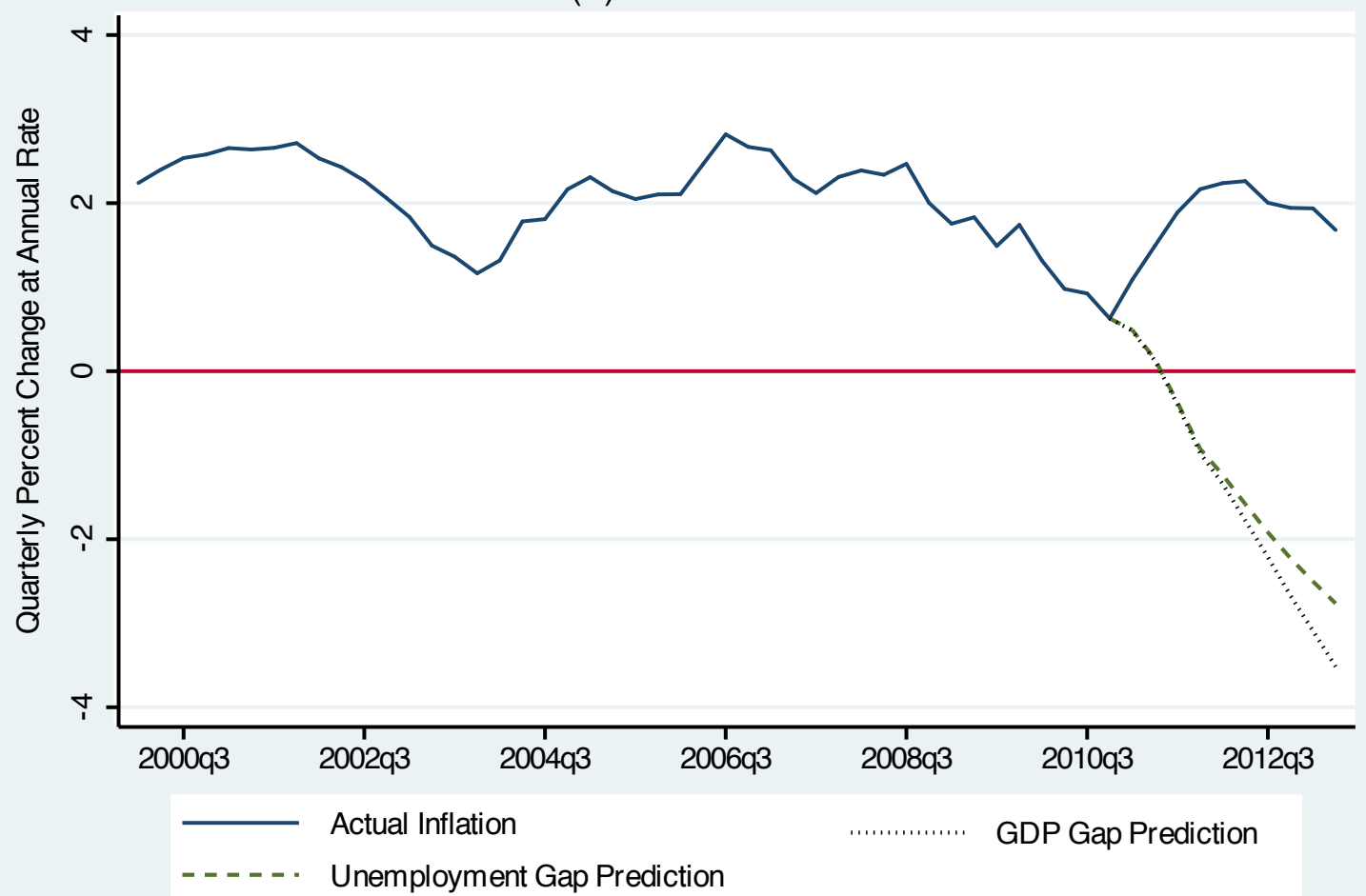

(B) Core PCE Inflation

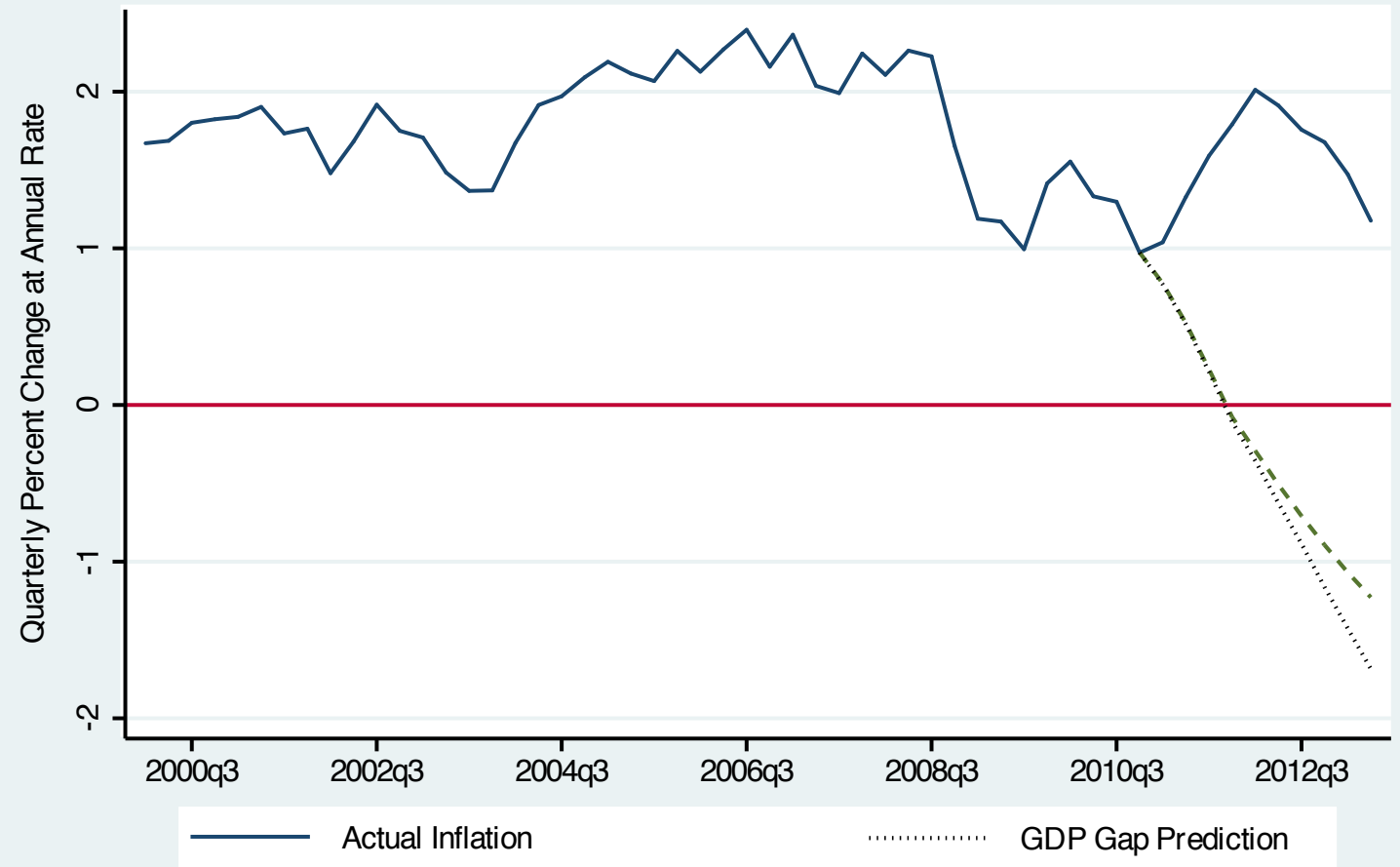

- - - - - . Unemployment Gap Prediction 
Figure 3: Dynamic Predictions of Inflation for 2008:1-2013:2 Using 1960:1-2000:4 Sample Period 4-Quarter Moving Average

(A) Core CPI Inflation

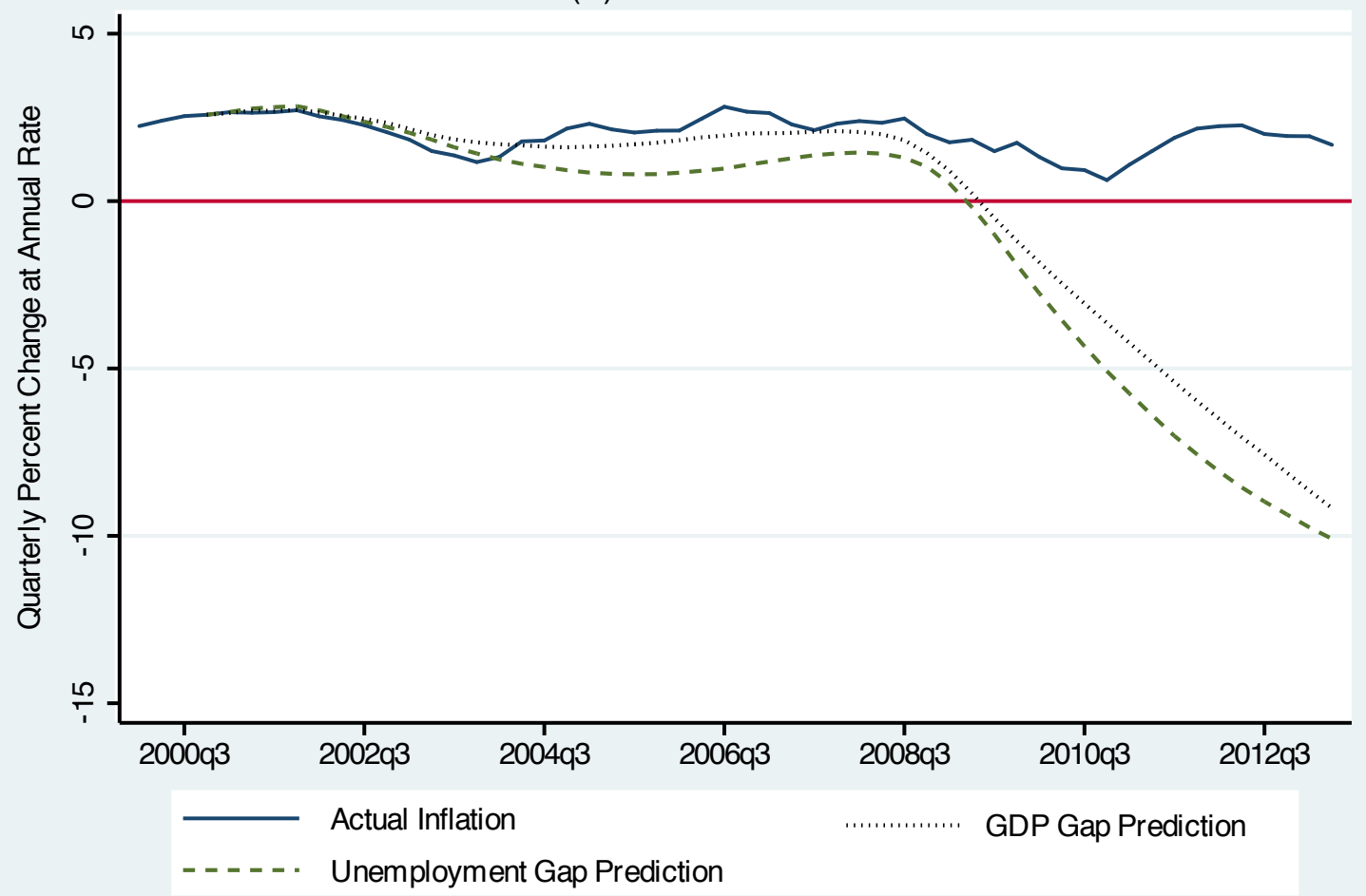

(B) Core PCE Inflation

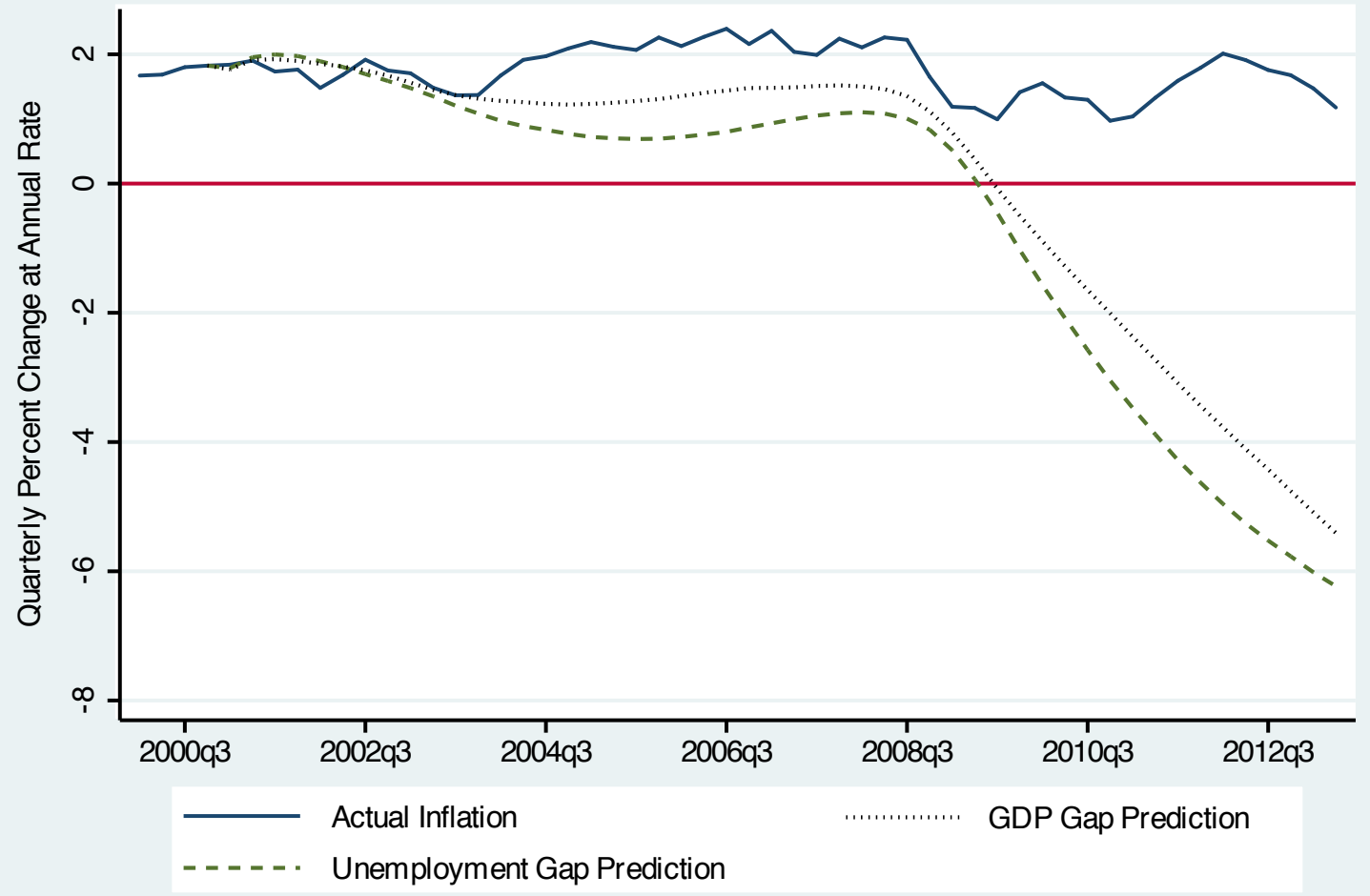


Figure 4: Time-Varying Slope Coefficient For Unemployment Gap Rolling 40-Quarter Samples Centered at Date Shown

(A) Core CPI Inflation
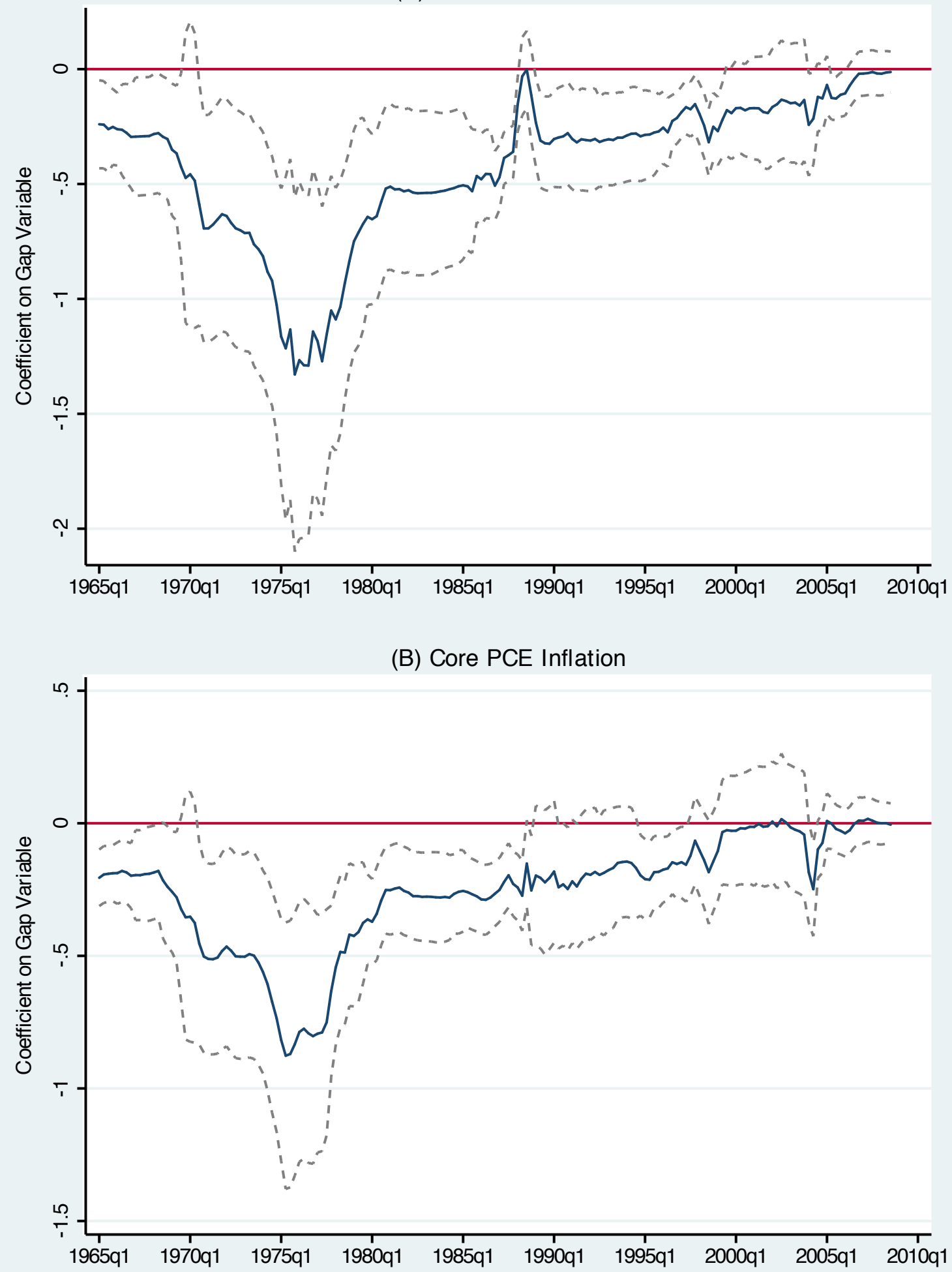

Note: Dashed lines are 95-percent confidence bands. 
Figure 5: Quandt Likelihood Ratio Test

(A) Core CPI Inflation

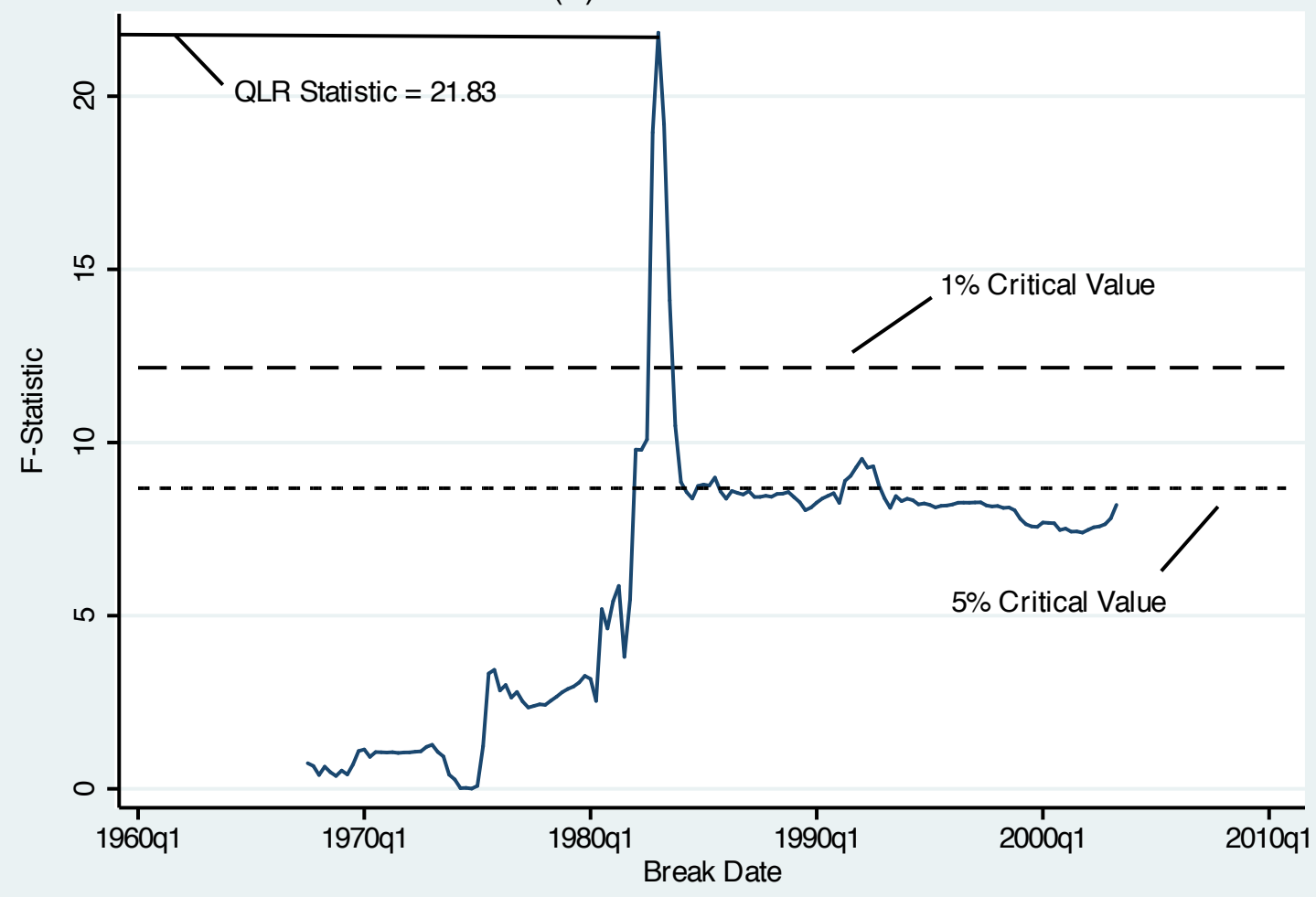

(B) Core PCE Inflation

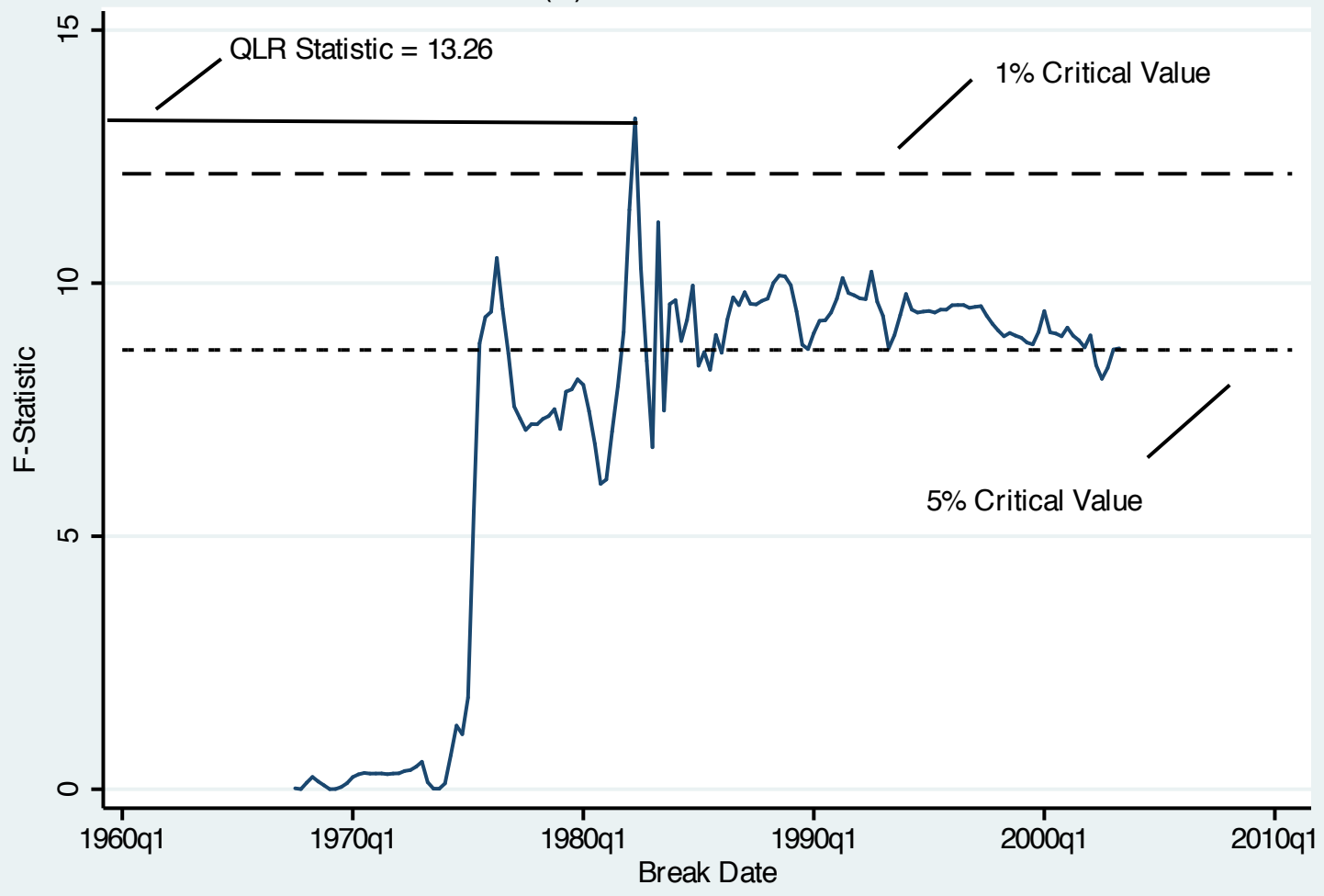


Figure 6: Dynamic Predictions of Inflation for 2008:1-2013:2 Using 1983:1-2007:4 Sample Period 4-Quarter Moving Average

(A) Core CPI

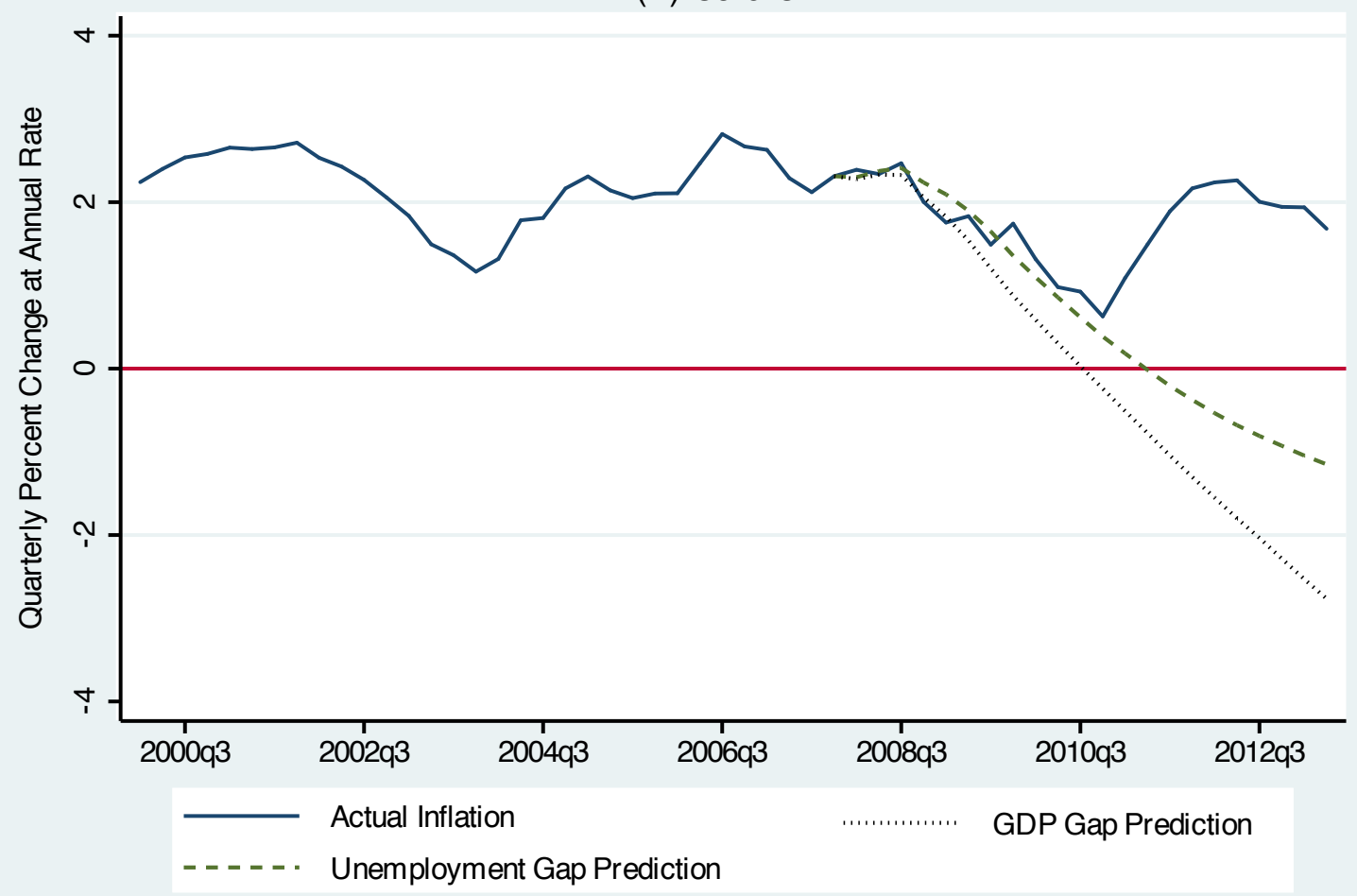

(B) Core PCE

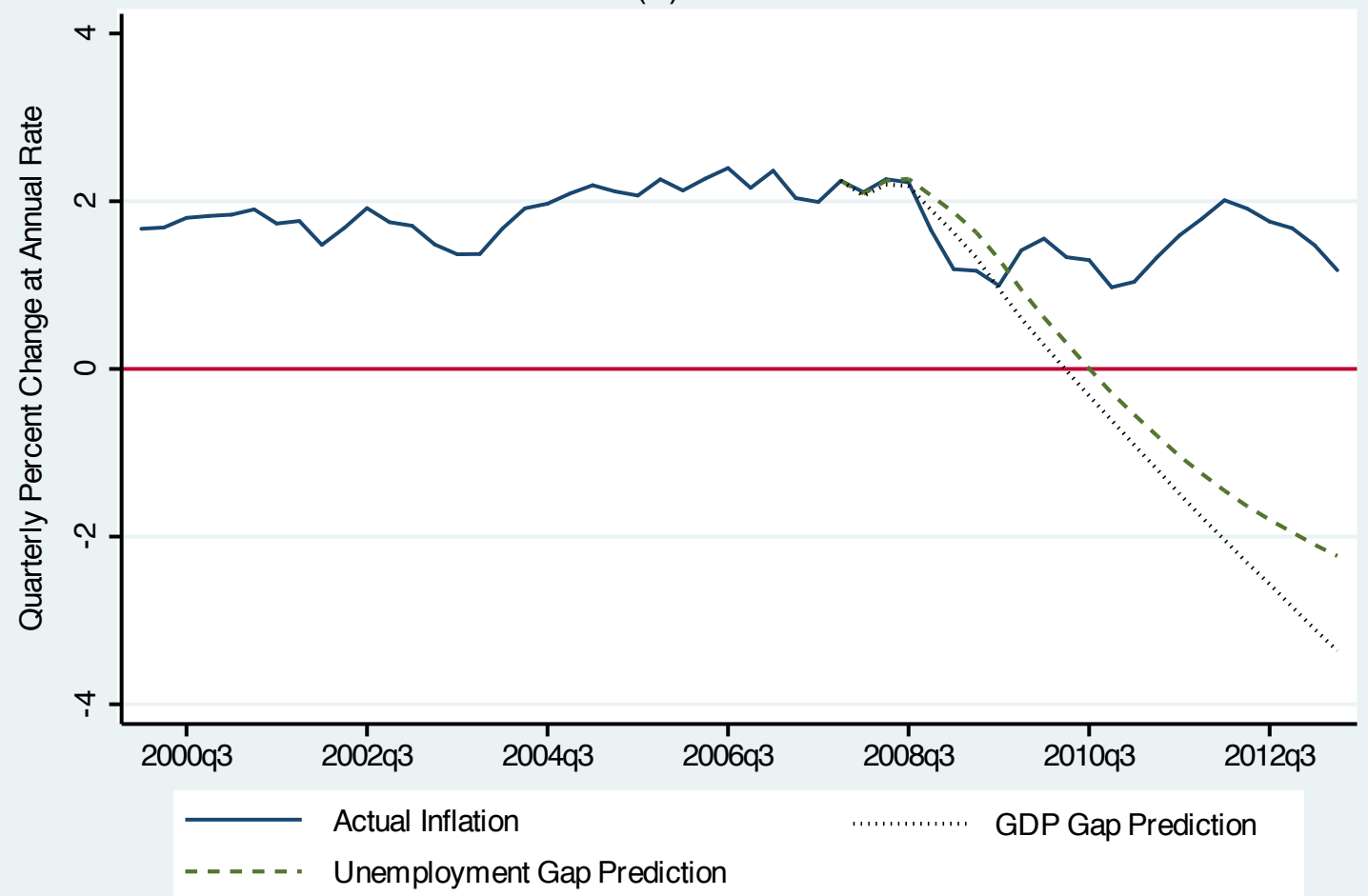


Figure 7: Dynamic Predictions of Inflation for 2008:1-2013:2, 4-Quarter Moving Average Coefficient Estimates from 40-Quarter Sample Period Centered at 2007:4

(A) Core CPI Inflation

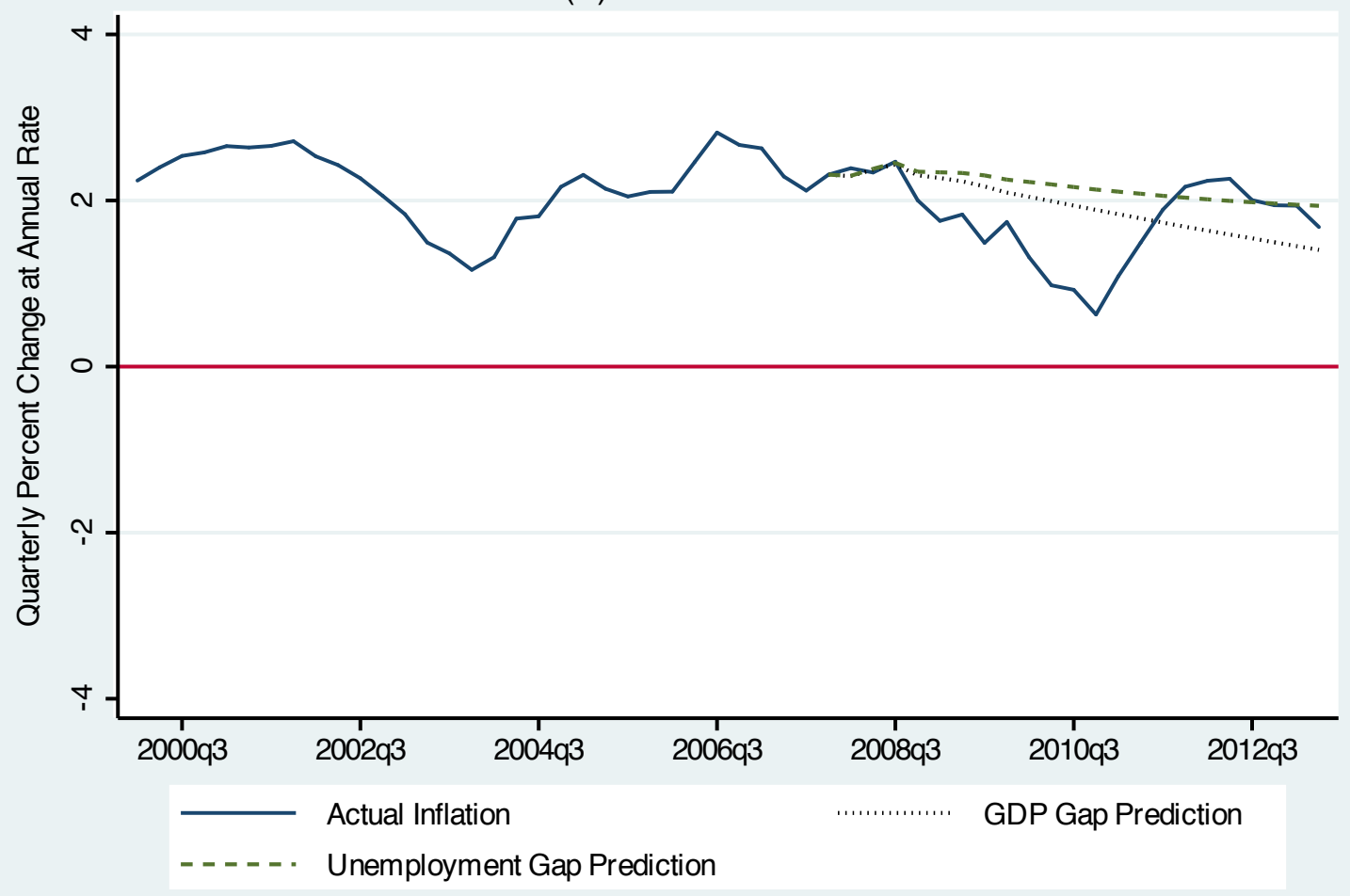

(B) Core PCE Inflation

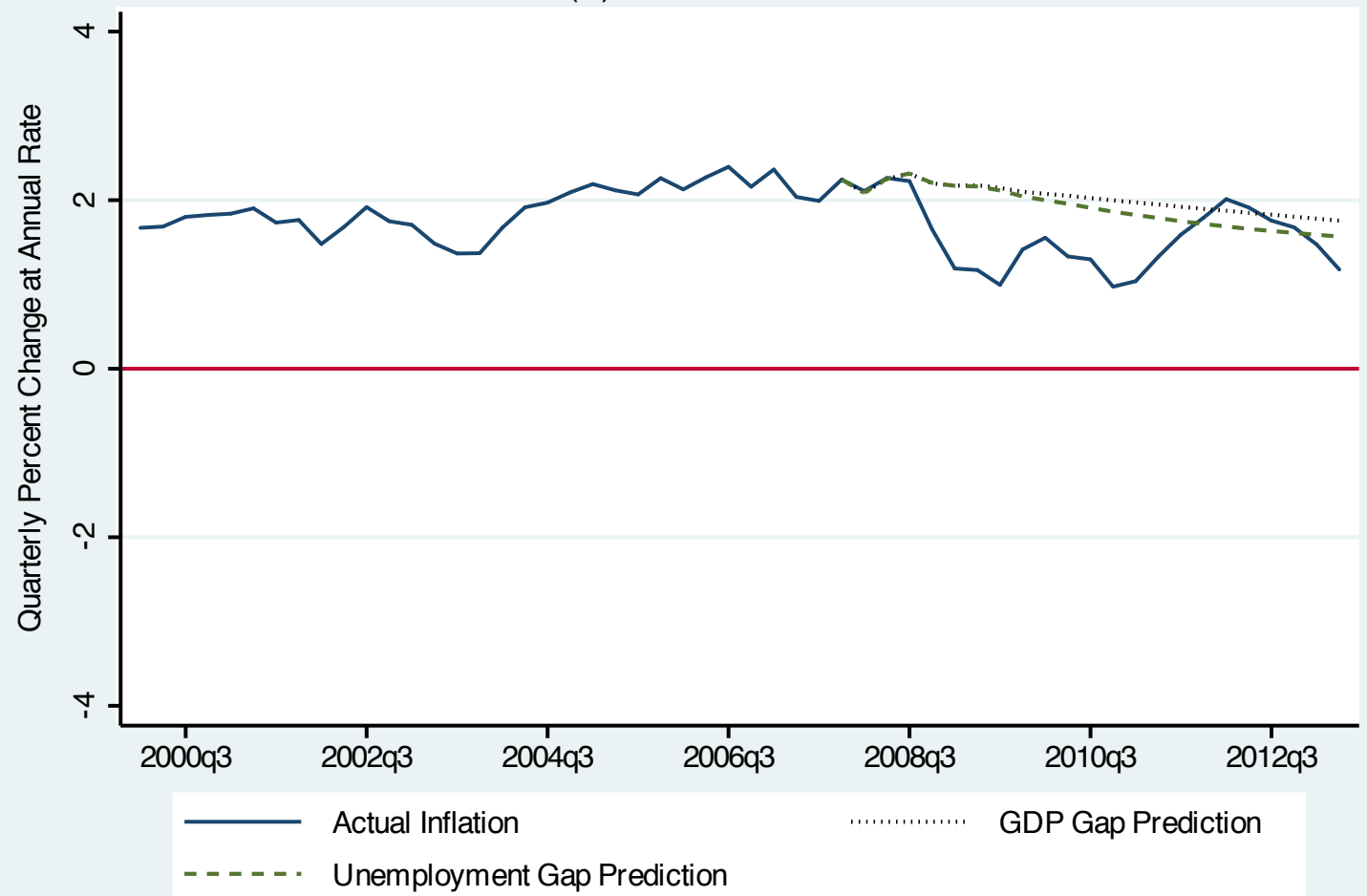


Figure 8: Regional Dispersion of Economic Conditions

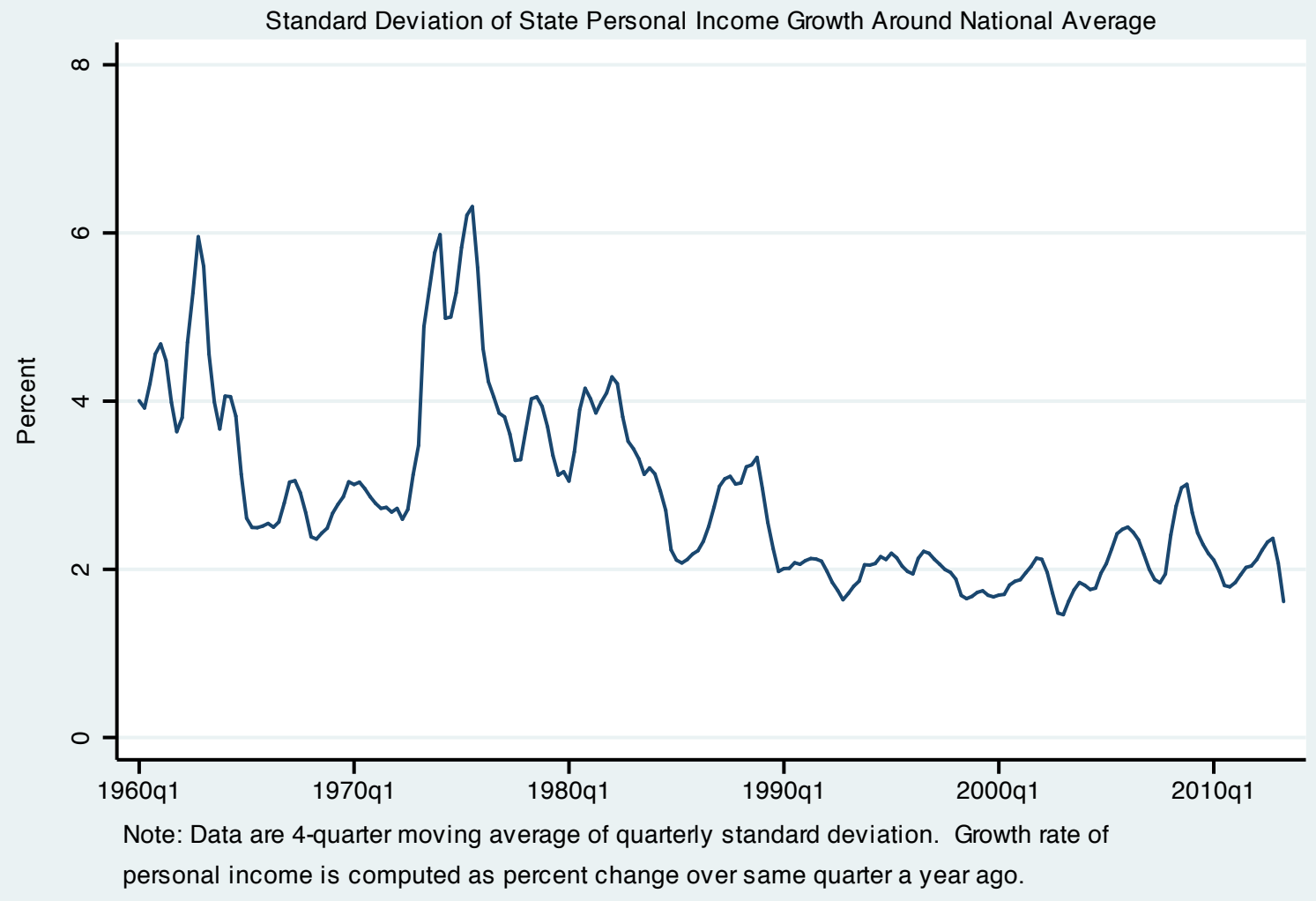


Figure 9: Measures of the Inflation Environment

Rolling 40-Quarter Samples Centered at Date Shown

(A) Core CPI Inflation

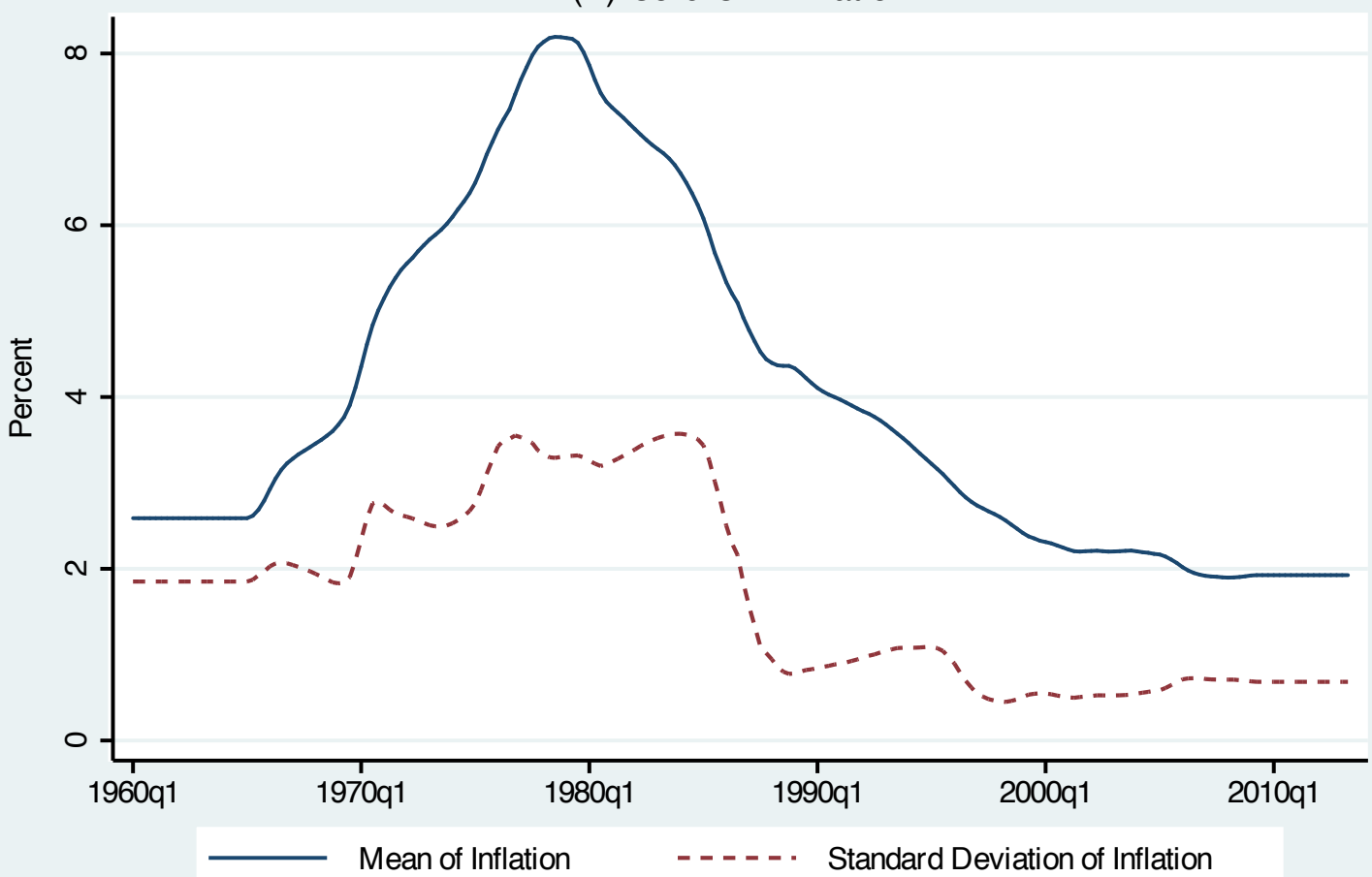

(B) Core PCE Inflation

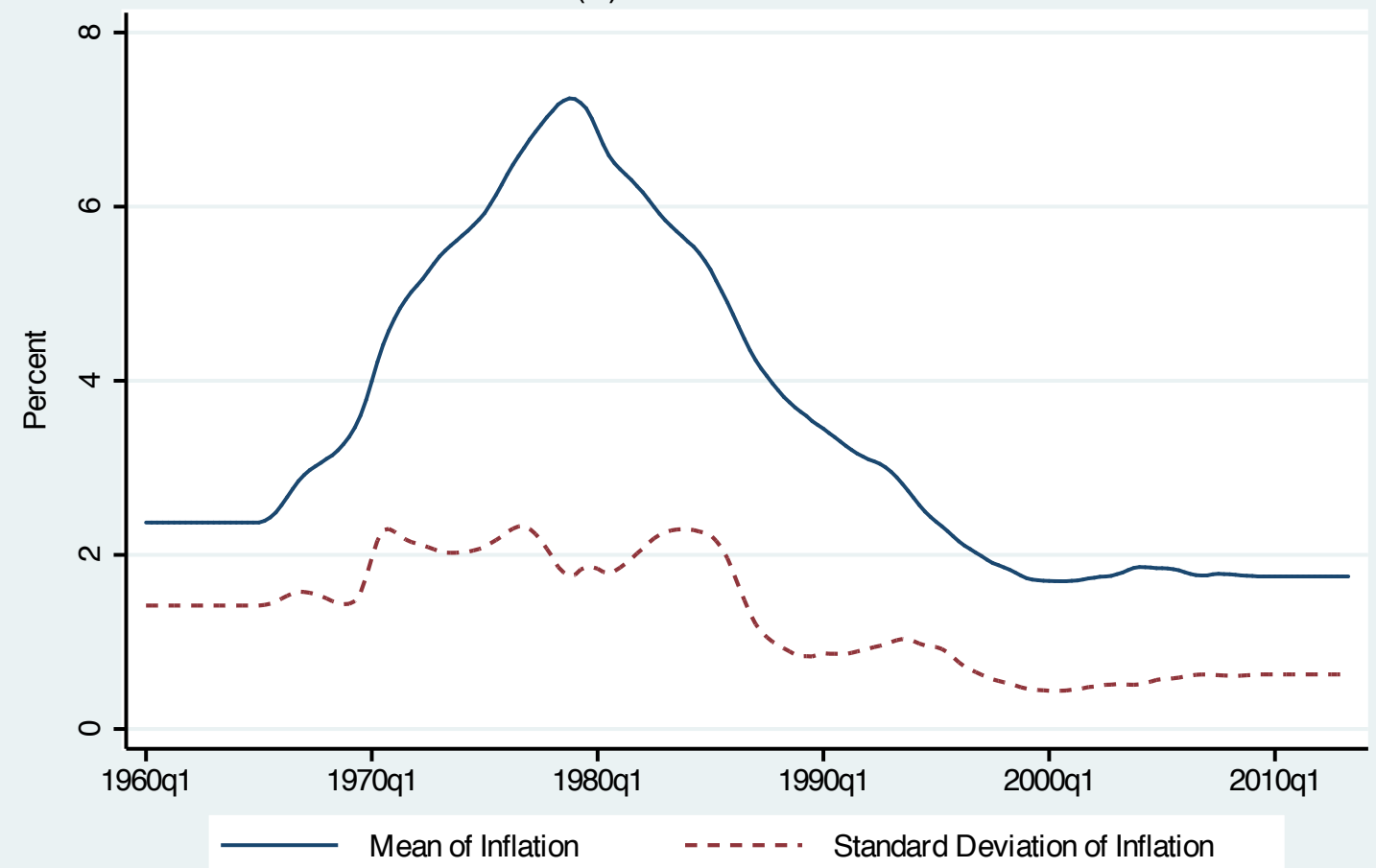

Note: Data are 4-quarter moving average of the respective series. 
Figure 10: Dynamic Predictions of Inflation for Models with Time Varying Slope 1960:1-2007:4 Sample Period, 4-Quarter Moving Average

(A) Core CPI Inflation

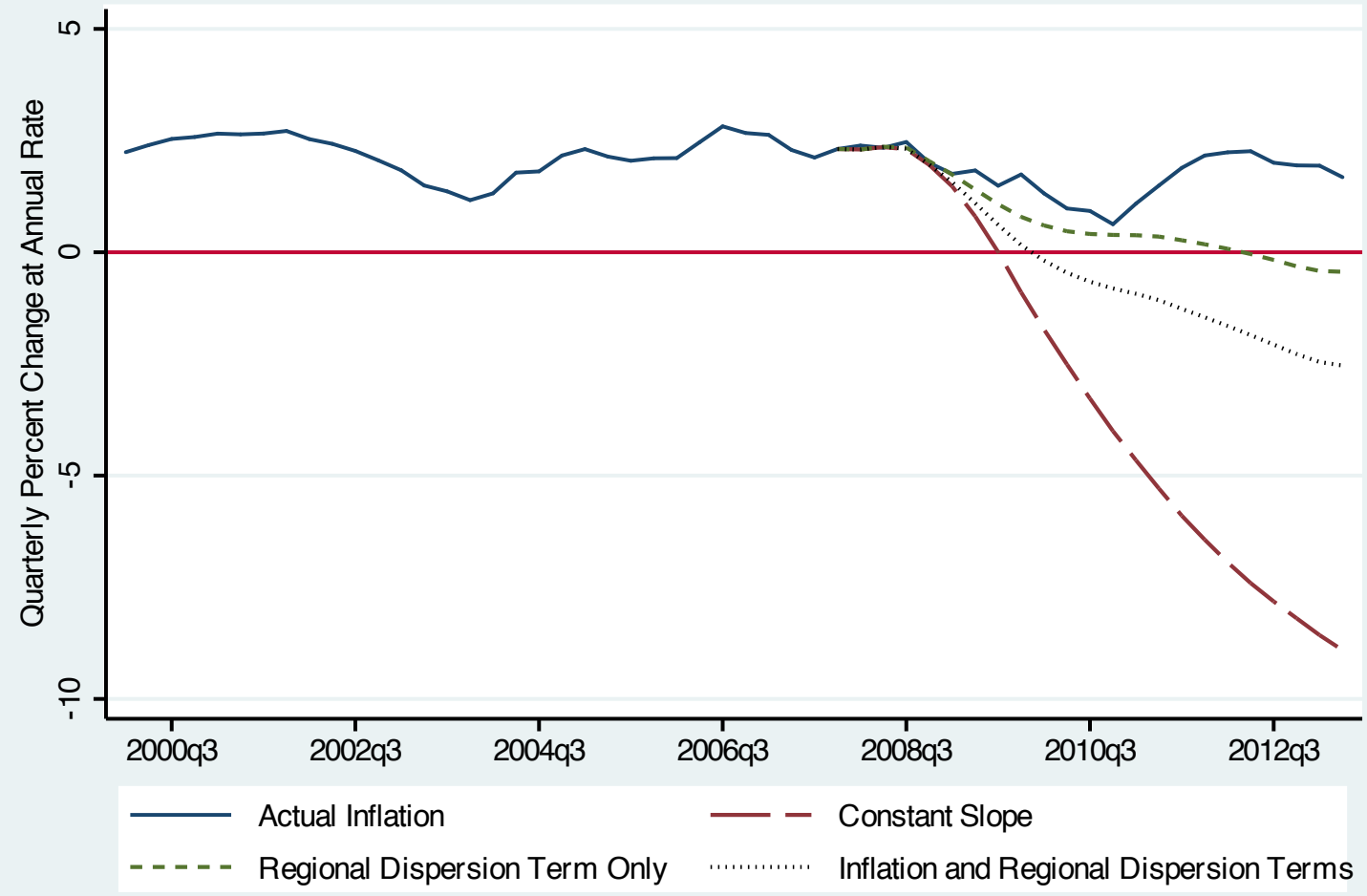

(B) Core PCE Inflation

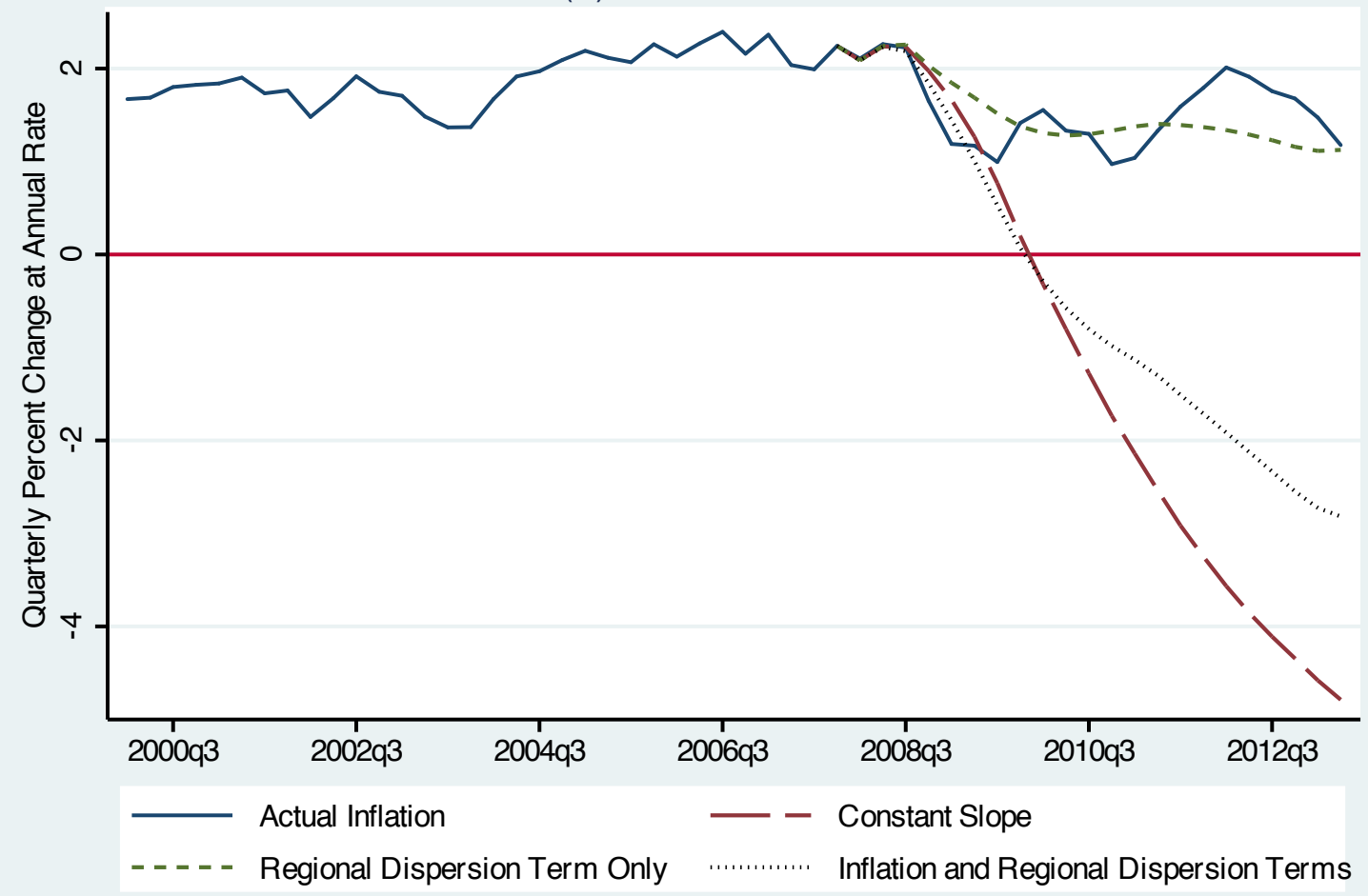


Figure 11: Dynamic Predictions of Inflation for Models with Time Varying Slope 1960:1-2000:4 Sample Period, 4-Quarter Moving Average

(A) Core CPI Inflation

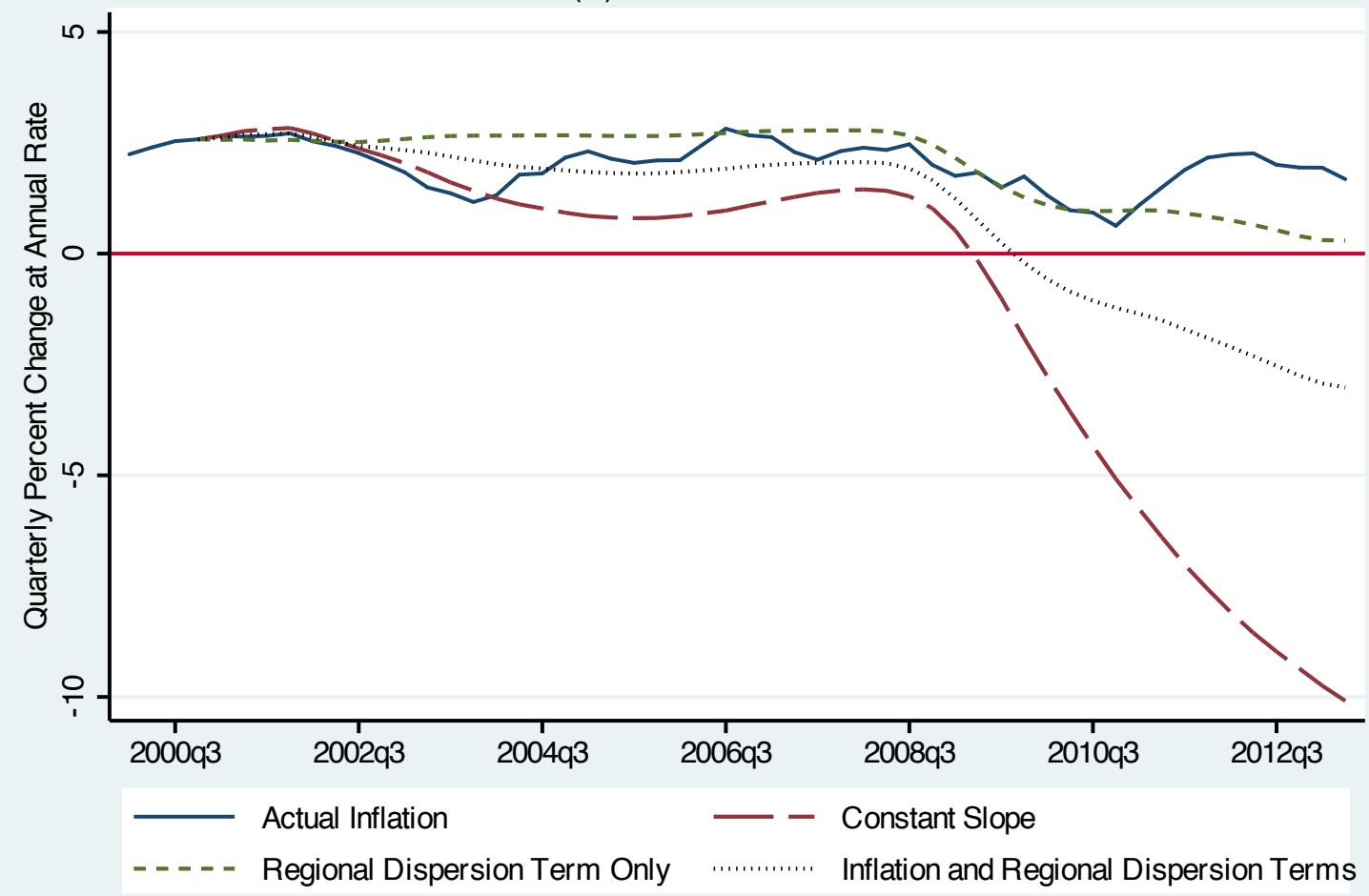

(B) Core PCE Inflation

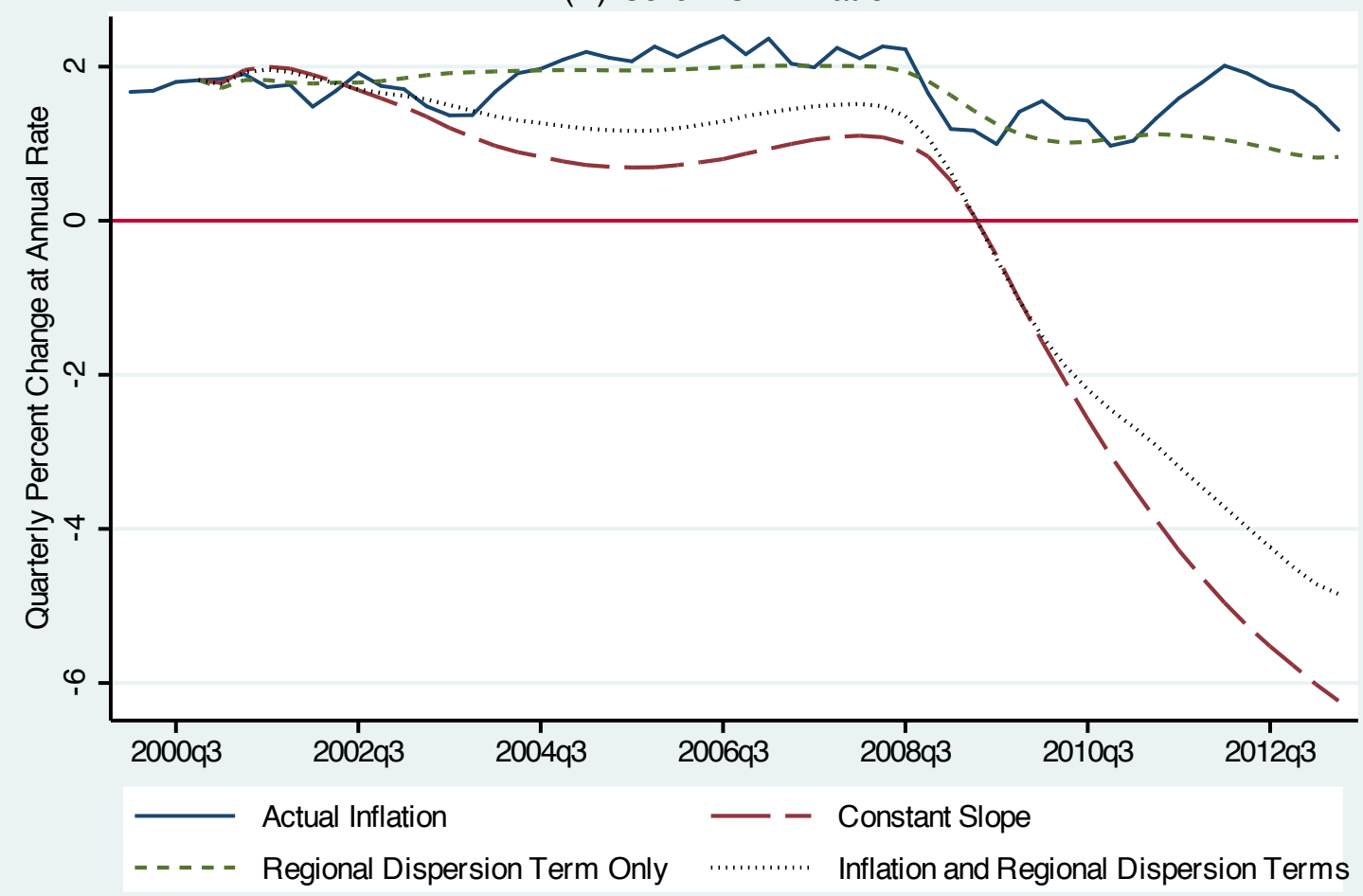


Figure 12: Dynamic Predictions of Quarterly Inflation Using 1960:1-2000:4 Sample Period

Core CPI Inflation

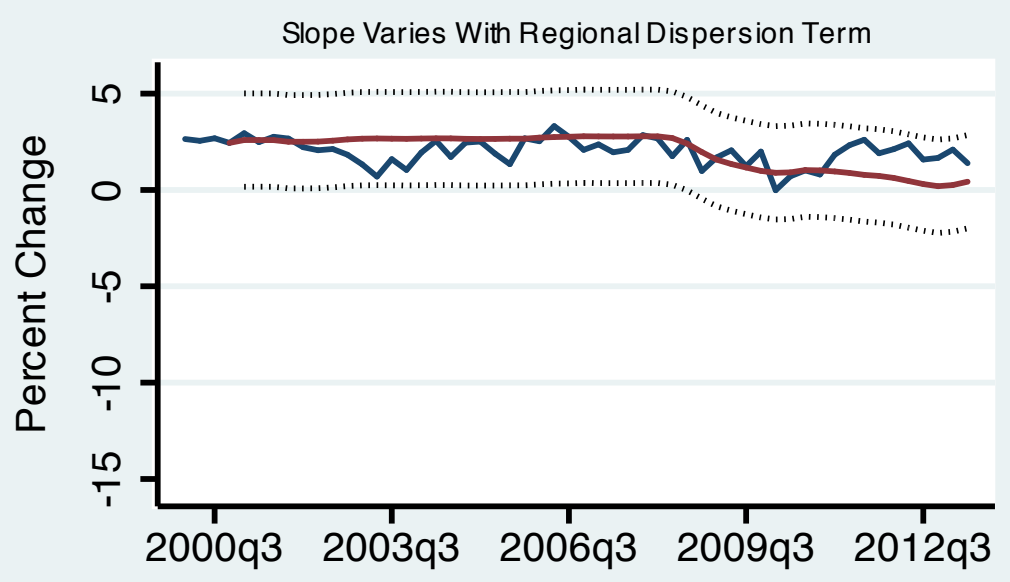

Core CPI Inflation

ConstantSlope

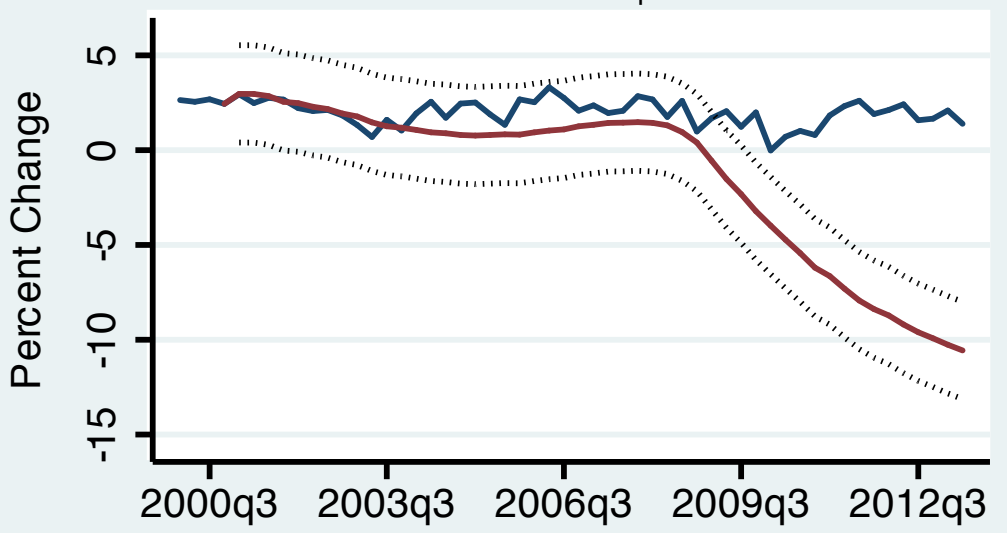

Core PCE Inflation

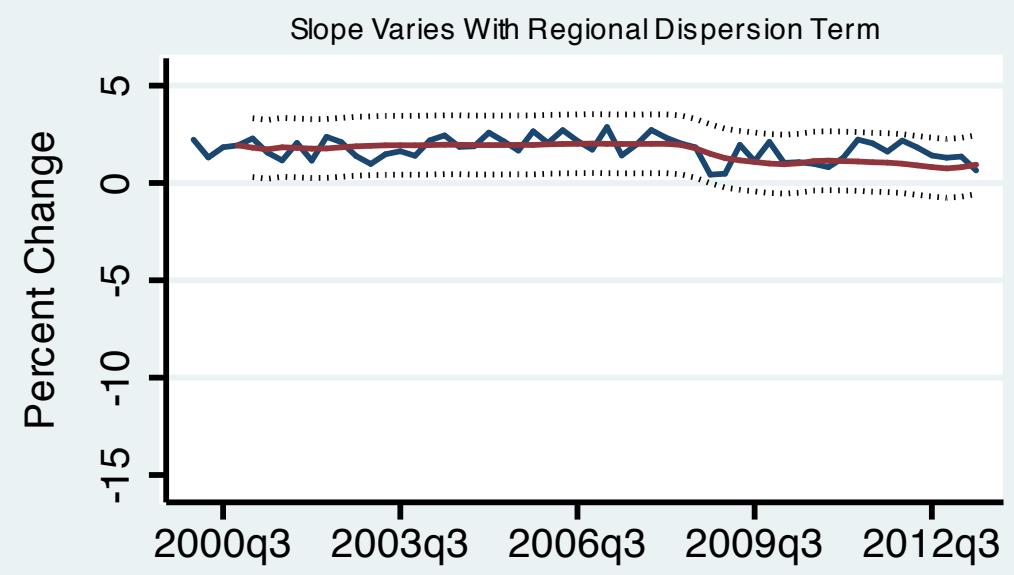

Core PCE Inflation

ConstantSlope

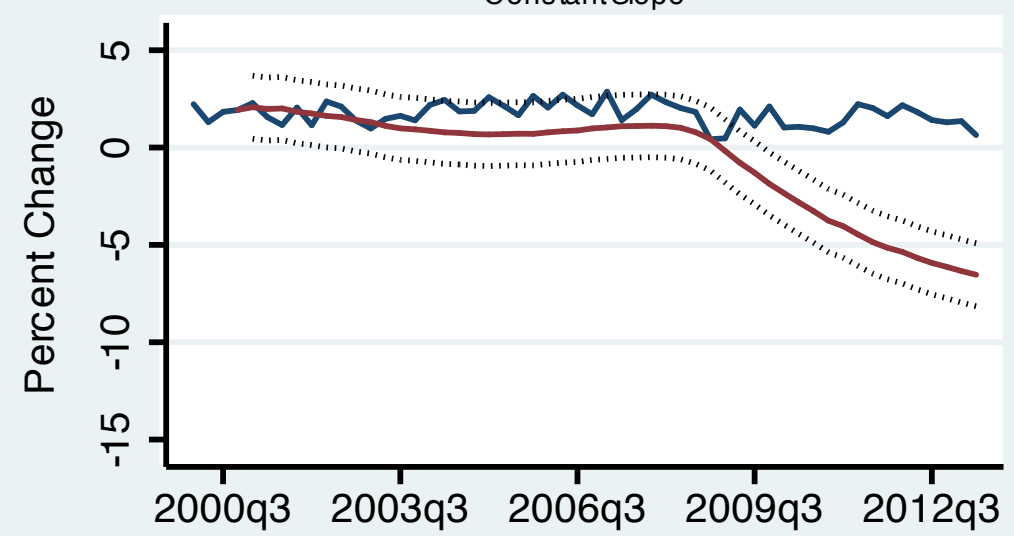

Note: Dotted lines are 90-percent confidence bands around prediction. 
Figure A1: Dynamic Predictions of Inflation for 2008:1-2013:2 Using New Keynesian Specification 1960:1-2007:4 Sample Period, 4-Quarter Moving Average

(A) Core CPI Inflation

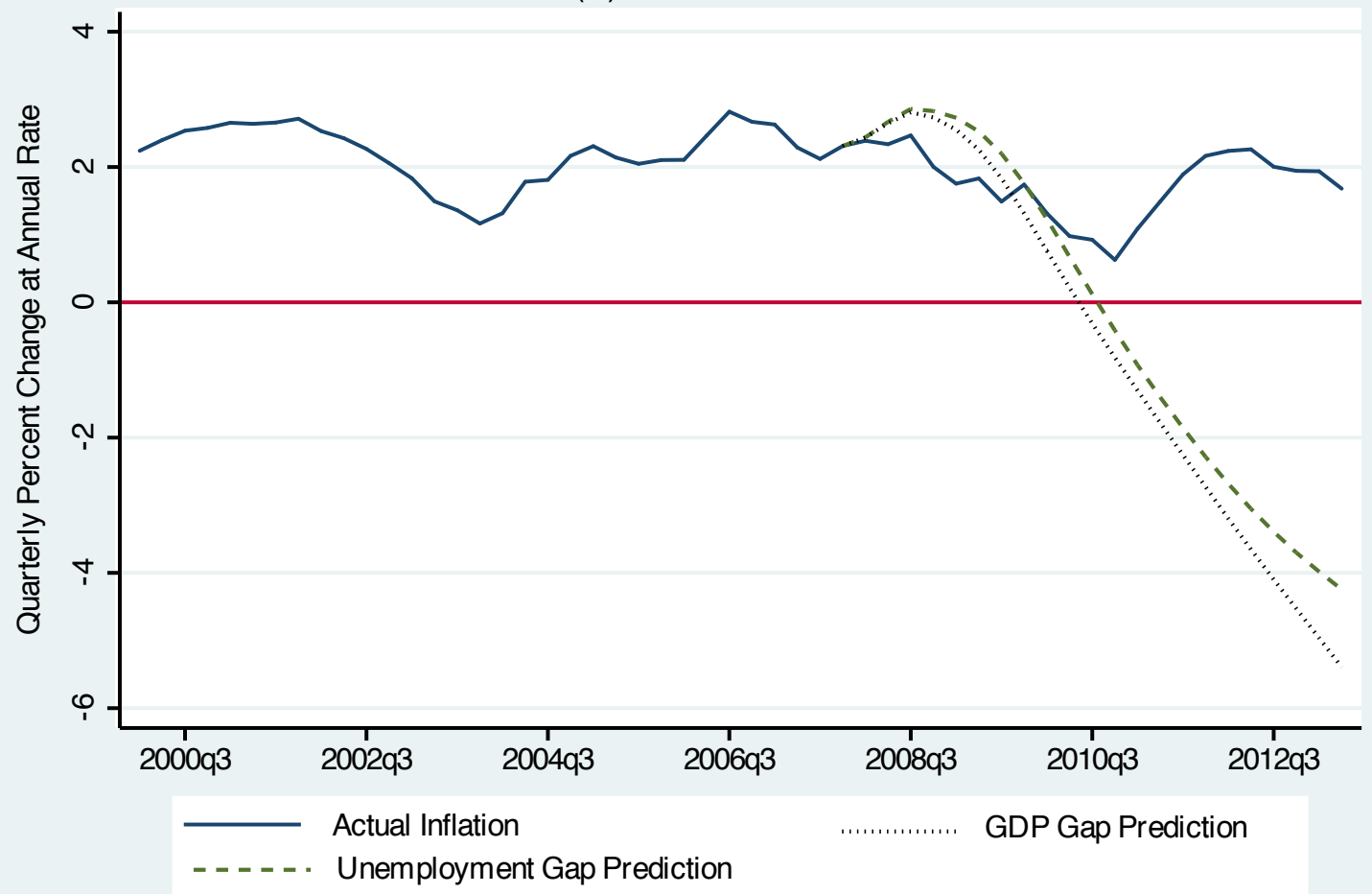

(B) Core PCE Inflation

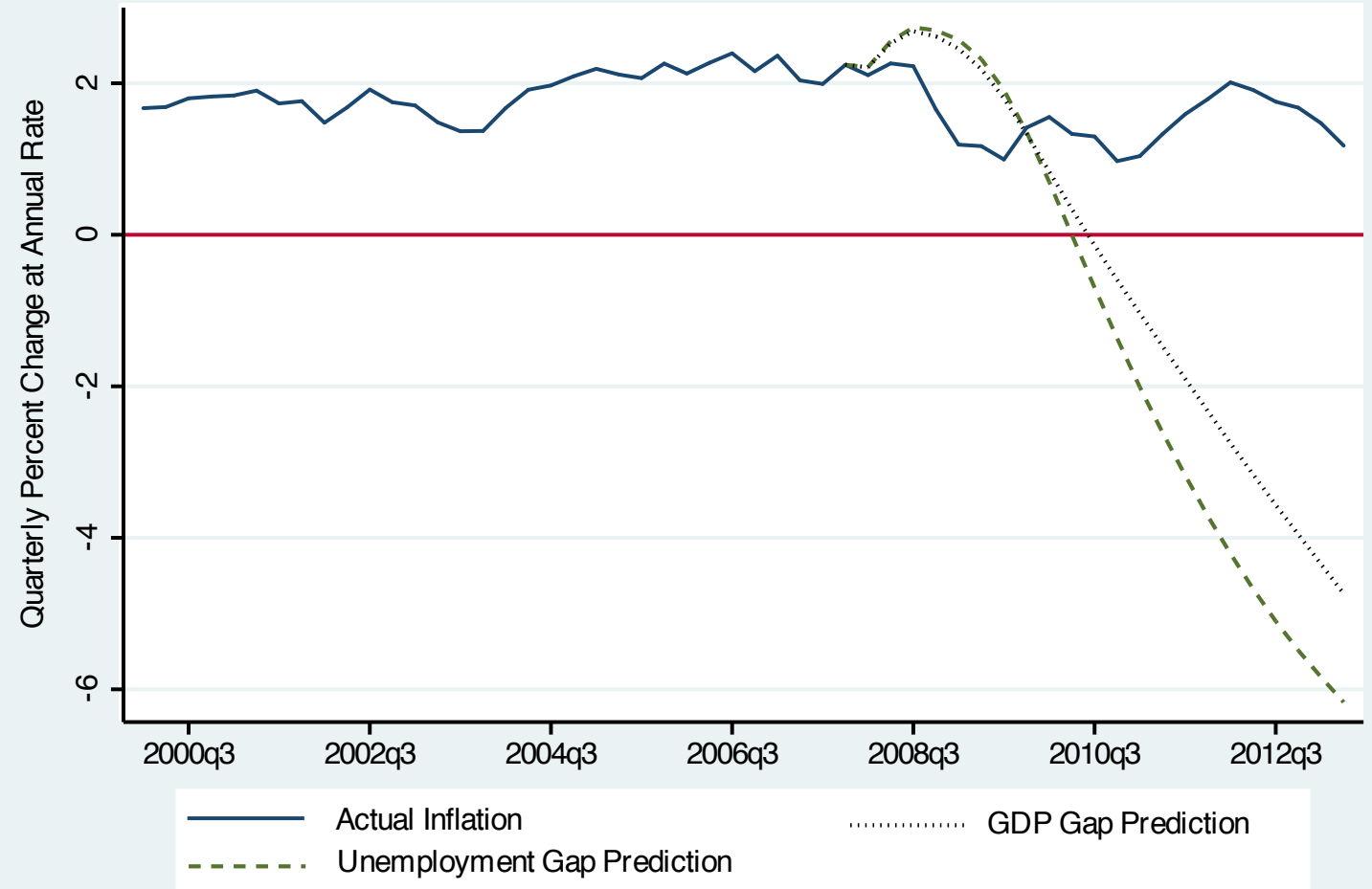

